1

2

3

4

5

6

8

9

10

11

12

13

14

\title{
Oiling the gears of memory: quercetin exposure during memory formation, consolidation, and recall enhances memory in Lymnaea stagnalis
}

(1)

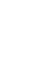

Running Title: Memory enhancement and quercetin

Veronica Rivi ${ }^{1,2 *}$, Anuradha Batabyal ${ }^{2}$, Cristina Benatti ${ }^{3 ; 4}$, Johanna MC Blom ${ }^{1,4}$,

Fabio Tascedda ${ }^{3,4,5}$ and Ken Lukowiak ${ }^{2}$

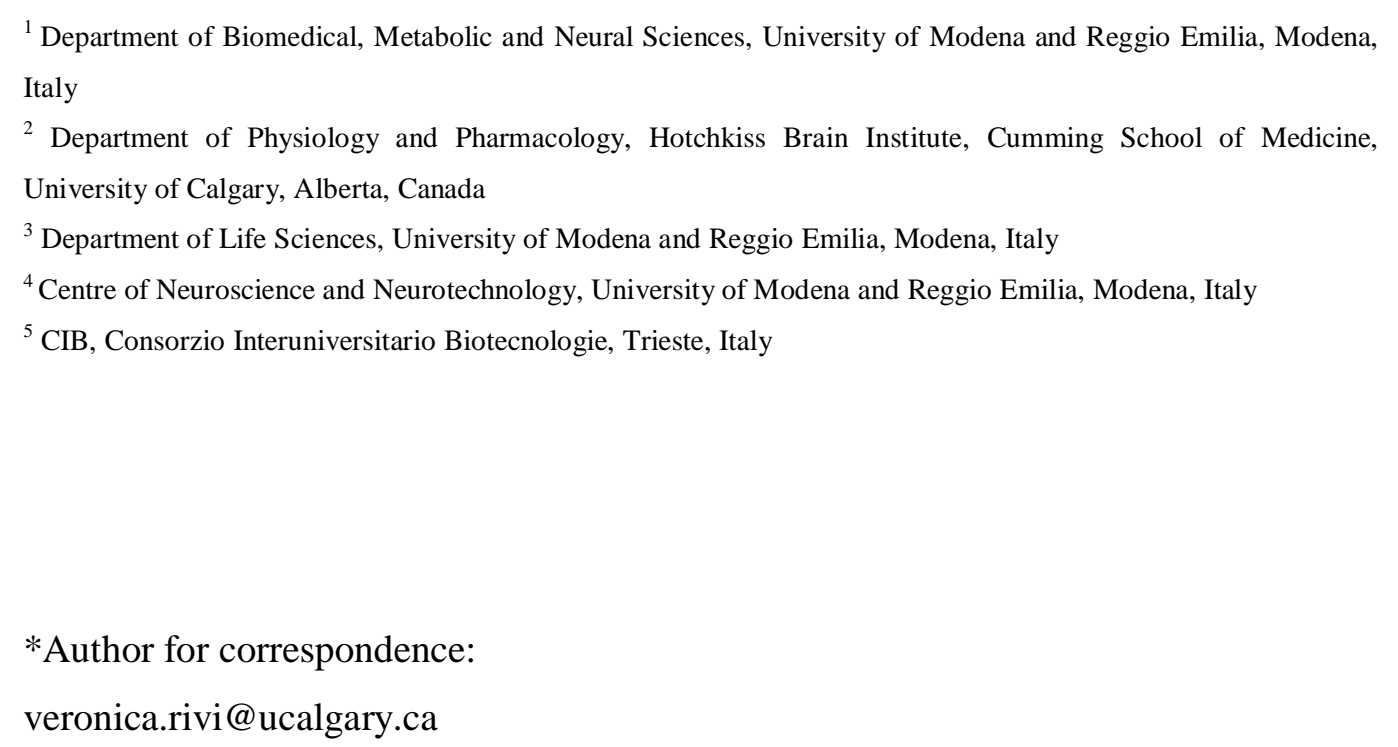

5 Summary Statement: Quercetin enhances long-term memory formation acting on the different phases of memory formation, consolidation, and recall.

Keywords: CREB, long-term memory, invertebrates, flavonoids 


\section{Abstract}

Memory formation (short-term, intermediate-term, and long-term) is an integral process of cognition which allows individuals to retain important information and is influenced by various intrinsic and extrinsic factors. A major extrinsic factor influencing cognition across taxa is diet, which may contain rich sources of molecular agents with antioxidant, anti-inflammatory, and memory enhancing properties that potentially enhance cognitive ability. A common and abundant flavonoid present in numerous food substances is quercetin $(\mathrm{Q})$ which is also known to upregulate cyclic AMP response element binding protein (CREB) in several animals including our model system Lymnaea stagnalis. Since CREB is known to be involved in long term memory (LTM) formation, we investigated the role of Q-exposure on memory formation, consolidation, and recall during operant conditioning of aerial respiratory behaviour in Lymnaea. Snails were exposed to Q $3 \mathrm{~h}$ before or after training to ascertain its effects on LTM. Additionally, we investigated the effect of the combined presentation of a single reinforcing stimulus (at $24 \mathrm{~h}$ post-training or $24 \mathrm{~h}$ before training) and Q-exposure on both LTM formation and reconsolidation. Our data indicate that Q-exposure acts on the different phases of memory formation, consolidation, and recall leading to enhanced LTM formation.

\section{Introduction}

Learning is the ability to acquire new knowledge, whereas memory is the process of storing, recalling, and reconstructing that knowledge over time (Kandel et al., 2014; Zlotnik and Vansintjan, 2019). Memories are not only essential for survival but are also major determinants of "who we are" (Milner et al., 1998). In fact, by regulating decision-making processes and influencing emotional reactions, they shape our very identity (Brem et al., 2013; Wilson and Ross, 2003).

Memory, based on the duration of its persistence, can be classified into short-term memory (STM, lasting minutes), intermediate-term memory (ITM, lasting 2-3 h), and long-term memory (LTM, persisting for at least 24h and sometimes for the entire lifetime; Braun and Lukowiak, 2011; Lukowiak et al., 2000; Sangha et al., 2003a,b). LTM is functionally dynamic and includes several temporal phases, such as encoding, consolidation, retrieval, and reconsolidation (Bisaz et al., 2014; Marra et al., 2013; 
Lukowiak et al., 2000; Rosenzweig et al., 1993). In recent decades, extraordinary progress has been made in demonstrating the molecular and cellular mechanisms underlying LTM, providing insight into how memories might also be enhanced. In this regard, studies in invertebrate models such as Aplysia californica (Conte et al., 2017; Hawkins et al., 2006; Philips et al., 2006) and Drosophila melanogaster (Davis, 2011; Isabel et al., 2004; Matsuno et al., 2015; Widmer et al., 2018) have paved the way to the elucidation of the conserved molecular and cellular basis of memory across taxa. A key feature of LTM is that a newly encoded memory initially exists in a fragile state and, over time, becomes increasingly resistant to disruption. With retrieval or reactivation, a consolidated memory can re-enter a labile state until it is restabilized through a process of reconsolidation (Nader et al., 2000; Alberini, 2009, 2011; Bisaz et al., 2014; Squire et al., 2015). During both consolidation and reconsolidation processes, memory is susceptible to modification by environmental factors, such as stress and lifestyle choices (McKenzie and Eichenbaum, 2011).

One key lifestyle choice that impacts the strengthening or weakening of the memory trace is diet (Swinton et al., 2018). Growing evidence suggests that a group of dietaryderived phytochemicals, known as flavonoids, may improve LTM formation, consolidation, storage, and retrieval (Ayaz et al., 2019; Fruson et al., 2012; Haleagrahara et al., 2011; Havsteen, 2002; Knezevic and Lukowiak, 2014; Letenneur et al., 2007; Socci et al., 2017). A multitude of pharmacological studies reported that regular dietary consumption of flavonoids and flavonoid-rich foods can improve various cognitive dysfunctions and dementia-like alterations in different animal models (Bakoyiannis et al., 2019; Macready et al., 2009; Mastroiacovo et al., 2015; Socci et al., 2017; Spencer, 2007a; Yevchak et al., 2008). The positive cognitive effects of flavonoids in mammals have been attributed to the protection of neural functioning, stimulation of neuronal regeneration, and increased blood flow to the brain (Macready et al., 2009; Mastroiacovo et al., 2015; Schroeter et al., 2007; Spencer, 2007; Vauzour et al., 2007; Williams and Spencer, 2012; Yevchak et al., 2008). 
93 Quercetin (Q, 3,3', $4^{\prime}, 5,7 \square$ pentahydroxyflavone) is one such flavonoid which is 94 widely distributed in fruits and vegetables, like apples, berries, onions, asparagus, capers, and red leaf lettuce (Manach et al., 2004, 2005). Q has antioxidant properties and is able to scavenge free radicals and protect neuronal cells from neurotoxicity caused by oxidative stress (Ahmad et al., 2015; Cushnie and Lamb, 2005; Eggler et al., 2008; Kong et al., 2000; Morel et al., 1993a; Robak and Gryglewski, 1988). Unfortunately, to date, the vast majority of the studies investigating the effects of $Q$ on memory has been performed on aged individuals or animal models of neurodegenerative diseases (Ansari et al., 2009; Bhutada et al., 2010; Broman-Fulks et al., 2012; Haleagrahara et al., 2011; Jayasena et al., 2013; Karimipour et al., 2019; Khan et al., 2018; Mandel and Youdim, 2004; Morel et al., 1993; Nakagawa et al., 2016; Reznichenko et al., 2006; Spencer, 2007, 2008; Williams and Spencer, 2012; Yoshida et al., 1990). Thus, there is a paucity of studies about the memory-enhancing effect of $\mathrm{Q}$ on healthy individuals. However, studies involving $\mathrm{Q}$ treatment on cognitively impaired animal models showed several molecular mechanisms that can enhance memory. Among them, the extracellular signal-regulated kinase (ERK1/2) and the protein kinase $\mathrm{B}(\mathrm{PKB} / \mathrm{Akt})$ signalling pathways are important as they activate the response element-binding protein (CREB) family of transcription factors which, in turn, play a key role in regulating the genes necessary for synaptic plasticity (Finkbeiner et al., 1997; Spencer, 2007; Spencer et al., 2003; Vauzour et al., 2007). In particular, the transcriptional activator CREB1 is a core component of the molecular switch that converts STM to LTM (Finkbeiner et al., 1997; Kida, 2012; Silva et al., 1998; Suzuki et al., 2011). That is, by increasing the expression levels of various neurotrophins, CREB regulates memory formation, consolidation, and reconsolidation in a wide range of animal models, from invertebrates to mammals (Alberini, 2009, 2011; Bozon et al., 2003; Stevens, 1994; Yin and Tully, 1996). Therefore, it is not surprising that CREB and the signalling pathways leading to its activation are attractive targets for treatment aimed at improving memory function, in both diseased and healthy individuals (Barco et al., 2003; Khan et al., 2018; Tully et al., 2003).

Importantly for us here in the pond snail Lymnaea stagnalis (Linnaeus 1758) it was found that treatment with $\mathrm{Q}$ resulted in the upregulation of the orthologous gene of 
125 CREB1 (LymCREB1) 3h after exposure to Q (Batabyal et al., 2021). In recent years,

126

127

128

129

130

131

132

133

134

135

136

137

138

139

140

141

142

143

144

145

146

147

148

149

150

151

152

153

154

155

156 several studies from our lab have focused on how environmentally relevant stressors and bio-active compounds alter LTM formation in snails. Using Lymnaea as a model organism, it was shown for the first time in invertebrates that the flavonoid (-)Epicatechin present in cocoa and green tea enhances LTM following operant conditioning of aerial respiratory behaviour (Fernell et al., 2016; Fruson et al., 2012; Knezevic and Lukowiak, 2014). Using operant conditioning of aerial respiratory behaviour it has been shown that memory formation can be altered (i.e., enhanced or inhibited) by a number of different factors (Lukowiak et al., 1996; Lukowiak et al., 2000, 2010). Consistent with the studies in vertebrate models (Debiec et al., 2002; Kida et al., 2002; Milekic and Alberini, 2002), new RNA and protein synthesis are required for LTM formation and reconsolidation in Lymnaea (Sangha, Scheibenstock, and Lukowiak, 2003).

Here we investigated the role of a plant flavonoid, Q, on memory formation, consolidation, and reconsolidation. Following configural learning, Lymnaea exposed to $\mathrm{Q}$ show an upregulation of LymCREB1 which significatively enhanced LTM formation (Batabyal et al., 2021). Those results paved the way for our detailed study on the effects of Q on different LTM phases following operant conditioning of aerial respiratory behaviour. Here we assessed for the first time in an invertebrate model the effects of the exposure to Q on LTM formation, consolidation, and recall. We found that following the exposure of snails to $\mathrm{Q} 3 \mathrm{~h}$ before or after training and $3 \mathrm{~h}$ before a $24 \mathrm{~h}$ memory test that LTM formation was enhanced.

\section{Material and methods}

\section{Animals}

Lymnaea stagnalis were bred and raised in the snail facility at the University of Calgary from a strain of Lymnaea originally obtained from Vrije Universiteit in Amsterdam. We have designated these snails as the W-strain of Lymnaea to identify them from the other strains used in our laboratory. Other strains of Lymnaea have different memory abilities following operant conditioning of aerial respiration (Sunada et al., 2017). Adult snails (with a shell length of 2.5-3.0 cm) were maintained 
157

158

159

160

161

162

163

164

165

166

167

168

169

170

171

172

173

174

175

176

177

178

179

180

181

182

183

184

185

186

187

188

at a density of one snail per litre in artificial pond water (PW) under eumoxic (i.e., normal $\mathrm{O}_{2}$ levels; $\mathrm{PO}_{2}>9975 \mathrm{~Pa}$ ) conditions. Artificial $\mathrm{PW}$ consisted of distilled water containing 26g $1^{-1}$ Instant Ocean (Spectrum Brands, Madison, WI, USA), with added calcium sulphate dihydrate to create what we refer to as a 'standard calcium level' of $80 \mathrm{mg} \mathrm{l}^{-1}$ (Dalesman and Rundle, 2010; Knezevic et al., 2011). Animals were maintained at room temperature $\left(20-22{ }^{\circ} \mathrm{C}\right)$ on a schedule of $16 \mathrm{~h}: 8 \mathrm{~h}$ light: dark and had ad libitum access to romaine lettuce.

\section{Quercetin solution}

Quercetin (3,3',4',5,7-pentahydroxyflavone, Q) was obtained from Sigma Chemical Company (St Louis, MO, USA) and was dissolved in $0.1 \%$ (final concentration) dimethyl sulfoxide (DMSO). We prepared a Q solution by dissolving $50 \mu \mathrm{l}$ in $500 \mathrm{ml}$ of pond water (PW).

\section{Aerial respiratory behaviour}

Lymnaea stagnalis is a bimodal breather. In normal oxygenated conditions cutaneous respiration prevails; however, when in hypoxic conditions it switches to aerial respiration via the respiratory orifice, the pneumostome (Lukowiak et al., 1996; Lukowiak et al., 2006). Aerial respiration can be easily monitored via observation of the pneumostome opening and closing. Individually labeled snails were placed in 1 litre beaker filled with $500 \mathrm{ml}$ of PW made hypoxic by vigorously bubbling N2 for 20 $\min \left(\leq 0.1 \mathrm{ml} \mathrm{O}_{2} \mathrm{l}^{-1}\right)$. Snails experiencing hypoxia increase their rate of aerial respiration (Lukowiak et al., 1996). Animals were acclimated for $10 \mathrm{~min}$ prior to observation. Bubbling was then reduced and continued at a slower rate during the following $30 \mathrm{~min}$ of breathing observation. In that way the environment was maintained hypoxic without disturbing snail activity. During the observation period aerial respiratory behaviour was recorded. In particular, we measured the amount of time the pneumostome was open for each snail without any tactile stimulation. This allowed us to compute the total breathing time in seconds for each snail. Following each breathing observation period, snails were returned to their home eumoxic aquaria. 
189

190

191

192

193

194

195

196

197

198

199

200

201

202

203

204

205

206

207

208

209

210

211

212

213

214

215

216

217

218

219

220

\section{A $0.5 \mathrm{~h}$ training session procedure for operant conditioning}

In all of the operant conditioning training sessions and tests for LTM, a gentle tactile stimulus (using a sharpened wooden applicator) was applied to the pneumostome area (i.e., the respiratory orifice) every time the snail began to open its pneumostome to perform aerial respiration (Lukowiak et al., 1996). We refer to this response as an 'attempted pneumostome opening'. This tactile stimulus only evoked pneumostome closure, without causing the animal to withdraw its foot and mantle area (i.e., the whole-animal withdrawal response) into its shell. Animals were given a $10 \mathrm{~min}$ acclimation period before the start of experiment, during which they could perform aerial respiration without receiving the negative reinforcement stimulus. The number of attempted pneumostome openings was recorded for each individual snail over the following $0.5 \mathrm{~h}$ training session. To determine whether LTM was formed, an identical procedure (i.e., a memory test) was performed at different times following the training session. The time of the training session was defined as 'T0', whereas the memory tests were defined as times after the T0. Between the conditioning (training and memory) phases snails were returned to their eumoxic home aquaria, where they were fed ad libitum and freely allowed to perform aerial respiration. Breathing behaviour was not monitored while snails were in the home aquaria.

\section{Single poke procedure}

Snails were placed in the hypoxic environment for a 10-min acclimation period without receiving any negative reinforcement stimulus. During the following $0.5 \mathrm{~h}$ of exposure to hypoxic PW they received a poke only the first time they began to open the pneumostome. Hence the term 'single poke procedure' (Karnik et al., 2012).

\section{Statistical analysis}

All our experimental treatments are independent from each other and have specific stimulus exposure timelines. Thus, we cannot combine the data in a meaningful manner for any grouped statistical analyses. We thus performed an individual pairedsample $t$ test for each experiment. In all analysis reported here, a type I error rate of 0.05 was used. All statistical analyses were performed using GraphPad Prism v. 9.00e for MAC® (GraphPad Software, Inc., La Jolla, CA, USA). 
222 Results

Effect of Q-exposure $3 \mathrm{~h}$ before or after a $0.5 \mathrm{~h}$ training session on LTM

We first determined if aerial respiratory behaviour was significantly influenced by Q.

Thus, total breathing time (TBT) was measured in standard hypoxia in a cohort of snails $(\mathrm{N}=10) 20 \mathrm{~h}$ before and $3 \mathrm{~h}$ after the exposure to $\mathrm{Q}$ for $1 \mathrm{~h}$. We found that TBT before and following exposure to $\mathrm{Q}$ was not significatively different $(\mathrm{t}=0.72, \mathrm{df}=9$, $\mathrm{p}=0.49)($ Figure 1A).

We next confirmed that in $\mathrm{W}$-strain snails a $0.5 \mathrm{~h}$ training session does not result in LTM formation (Figure 1B). We trained a naïve cohort of snails $(\mathrm{N}=10)$ with a $0.5 \mathrm{~h}$ training session (T0) and we tested for LTM 24h later (T24). These snails did not exhibit LTM as the number of attempted pneumostome openings at T0 and T24 was not statistically different $(\mathrm{t}=1.94, \mathrm{df}=9 ; \mathrm{p}=0.084)$.

Then, we wished to determine if the Q-exposure $3 \mathrm{~h}$ before training altered the ability of snails to form LTM (Figure 1C). Thus, a cohort of naïve snails $(\mathrm{N}=11)$ was exposed to $\mathrm{Q}$ for $1 \mathrm{~h}$ and three hours later received a $0.5 \mathrm{~h}$ training session (T0). We tested memory $24 \mathrm{~h}$ later (T24). Statistical analyses revealed that the number of attempted pneumostome openings at T24 was significantly reduced compared to T0 (t $=7.9 ; \mathrm{df}=10 ; \mathrm{p}<0.0001)$. Thus, Q-exposure $3 \mathrm{~h}$ before the $0.5 \mathrm{~h}$ training session enhanced LTM formation (i.e., LTM was present $24 \mathrm{~h}$ after T0).

Finally, we asked whether Q-exposure $3 \mathrm{~h}$ after a $0.5 \mathrm{~h}$ training session (T0) would also enhance LTM formation (Figure 1D). A cohort of naïve snails $(\mathrm{N}=11)$ was first trained in hypoxic PW (T0) and three hours later was placed for $1 \mathrm{~h}$ in eumoxic Qcontaining PW. Animals were then returned to their home aquaria and tested for LTM 20h later (i.e., at T24). Again, we found that at T24 the snails' respiratory behaviour was significantly reduced with respect to $\mathrm{T} 0(\mathrm{t}=8.74$; $\mathrm{df}=10 ; \mathrm{p}<0.0001)$. Thus, a 
253 Finally, we did control experiments to test the effect of the vehicle used to dissolve Q

254 (i.e., DMSO) on LTM enhancement. We found that the exposure to DMSO $3 \mathrm{~h}$ before

255 the $0.5 \mathrm{~h}$ training session did not result in LTM (T0: Mean \pm sem $=6.90 \pm 0.62 ;$ T24:

256 Mean \pm sem $=6.60 \pm 0.60 ; \mathrm{t}=0.81, \mathrm{df}=9 ; \mathrm{p}=0.43)$. Similar results were obtained

257 when DMSO exposure occurred $3 \mathrm{~h}$ after the $0.5 \mathrm{~h}$ training session (T0: Mean $\pm \mathrm{sem}=$

$2586.40 \pm 0.54 ; \mathrm{T} 24:$ Mean $\pm \mathrm{sem}=6.0 \pm 0.49 ; \mathrm{t}=0.82, \mathrm{df}=9 ; \mathrm{p}=0.43)$.

259

260

Together these data show that Q-exposure enhanced LTM formation in W-strain snails when snails experience $\mathrm{Q}$ either $3 \mathrm{~h}$ before or after a $0.5 \mathrm{~h}$ training session. Exposing snails to vehicle only $3 \mathrm{~h}$ before or $3 \mathrm{~h}$ after training did not result in LTM. Finally, Q-exposure did not alter normal homeostatic aerial respiration. Thus, we concluded that Q exposure is capable of enhancing LTM formation.

An obvious experiment to perform was to train a naïve cohort of snails in hypoxic PW $+\mathrm{Q}$ and determine if this also resulted in enhanced LTM formation. Quite unexpectedly, we found that the combination of hypoxic PW and Q severely suppressed snails' aerial respiratory behaviour, resulting in a sleep-like quiescent state that persisted for at least $2 \mathrm{~h}$ after ending the exposure (data not shown). This phenomenon is currently under investigation in our lab.

\section{Effect of the single-poke procedure and Q-exposure on LTM}

The demonstration that Q-exposure both $3 \mathrm{~h}$ before and after a $0.5 \mathrm{~h}$ training session procedure enhanced LTM formation and consolidation led us to investigate the effects of Q exposure on memory reconsolidation. Previous studies demonstrated that $24 \mathrm{~h}$ after a training procedure that only results in an intermediate-term memory (ITM) a residual memory trace is present despite the LTM phenotype being absent (Parvez et al., 2005, 2006). Here (Figure $\mathbf{2 A}, \mathbf{N}=11$ ), we found that a $0.5 \mathrm{~h}$ training session followed by the 'single poke' procedure $24 \mathrm{~h}$ after (i.e., T24) was not sufficient to enhance LTM at T48 (i.e., 48h after T0). In fact, there was no statistical difference between the number of attempted openings at $\mathrm{T} 48$ compared to $\mathrm{T} 0(\mathrm{t}=1.79, \mathrm{df}=10$; $\mathrm{p}=0.1)$. 
285 We next asked (Figure 2B) whether the combined exposure to Q and the single poke procedure performed $24 \mathrm{~h}$ after a $0.5 \mathrm{~h}$ training session procedure (i.e., at T24) would result in LTM when memory was tested $24 \mathrm{~h}$ later (i.e., T48). Thus, a naïve cohort of snails $(\mathrm{N}=11)$ was first trained in a $0.5 \mathrm{~h}$ training session (T0) and $20 \mathrm{~h}$ later was exposed to Q for $1 \mathrm{~h}$. Three hours later (i.e., 24h after T0 - T24), animals were placed in the hypoxic environment and received a poke only the first time they began to open the pneumostome (i.e., 'single poke' procedure).

LTM was then tested $24 \mathrm{~h}$ later (i.e., T48). In these snails a 48h LTM was shown $(\mathrm{t}=$ $3.02, \mathrm{df}=10 ; \mathrm{p}=0.012$ ), since the number of attempted pneumostome openings at T48 was significantly less than that in T0. Thus, combining Q-exposure $3 \mathrm{~h}$ before the 'single-poke procedure' resulted in an LTM when tested $48 \mathrm{~h}$ after T0.

This result led us to hypothesize that Q-exposure $3 \mathrm{~h}$ after the 'single-poke' procedure would also result in enhanced LTM formation. Thus, a naïve cohort of animals $(\mathrm{N}=$ 12) was tested using the same above behavioural procedure, but in these animals the exposure to Q occurred $3 \mathrm{~h}$ after the 'single poke' procedure performed at T24 (Figure 2C). We found that at T48 the snails' respiratory behaviour was significantly reduced with respect to $\mathrm{T} 0(\mathrm{t}=8.25, \mathrm{df}=11 ; \mathrm{p}<0.01)$, indicating that LTM persisted for at least $48 \mathrm{~h}$.

Finally, we showed in a cohort of snails $(\mathrm{N}=10)$ trained as above that when Qexposure was delayed by $20 \mathrm{~h}$ after the 'single-poke' procedure, LTM was not present (Figure 2D). That is, the number of attempted pneumostome openings between the T0 and T48 was not significantly different $(t=0.3, d f=9 ; \mathrm{p}=0.77)$. These data show that the 'single poke' procedure acts on a residual trace present $24 \mathrm{~h}$ after $\mathrm{T} 0$ and when combined with Q-exposure 3h before or after, enhanced LTM formation. 
313 Continuing with the effects of the 'single poke' procedure, we asked what effect, if

314

315

316

317

318

319

320

321

322

323

324

325

326

327

328

329

330

331

332

333

334

335

336

337

338

339

340

341

342

343

344

any, the 'single poke' would have if the snails received it before a $0.5 \mathrm{~h}$ training session. In a naïve cohort of snails (Figure $3 \mathbf{A} ; \mathrm{N}=10$ ) the single poke procedure $24 \mathrm{~h}$ before T0 did not result in LTM when tested $24 \mathrm{~h}$ later (i.e., T24). A paired t-test revealed that the number of attempted pneumostome openings at T24 was not significatively different from those at $\mathrm{T} 0(\mathrm{t}=0.58, \mathrm{df}=9, \mathrm{p}=0.59)$. Thus, LTM was not present. We then asked whether Q exposure $24 \mathrm{~h}$ before a $0.5 \mathrm{~h}$ training session (i.e., T0) resulted in enhanced LTM formation. Thus, a naïve cohort of snails $(\mathrm{N}=10)$ was exposed to Q $24 \mathrm{~h}$ before T0 and was then tested for LTM 24h later (Figure 3B). A paired t-test revealed that the number of attempted pneumostome openings at T24 was not significatively different from those at $\mathrm{T} 0(\mathrm{t}=1.33 \mathrm{df}=9, \mathrm{p}=0.21)$. That is, Q-exposure $24 \mathrm{~h}$ before a $0.5 \mathrm{~h}$ training session did not result in LTM formation.

We next asked if a combination of the 'single poke' procedure and Q-exposure $24 \mathrm{~h}$ before a $0.5 \mathrm{~h}$ training session (i.e., T0) would result in enhanced LTM formation. These data are presented in Figure 4. A naïve cohort of snails $(\mathrm{N}=10)$ was first exposed to $\mathrm{Q}$ for $1 \mathrm{~h}$ and $3 \mathrm{~h}$ later was subjected to the 'single poke' procedure (Figure 4A). Animals were then returned to their home aquaria for $20 \mathrm{~h}$ before being trained with a $0.5 \mathrm{~h}$ training session (T0). These snails were then tested for LTM $24 \mathrm{~h}$ later (i.e., T24). We found that the number of attempted openings at T24 was significantly less than at $\mathrm{T} 0(\mathrm{t}=7.23$; $\mathrm{df}=11 ; \mathrm{p}<0.0001)$. Thus, LTM was present. These data show that Q-exposure, combined with the single poke procedure $24 \mathrm{~h}$ before training, resulted in LTM formation. We next presented to a naïve cohort of snails $(\mathrm{N}=10)$ the single poke procedure first and then $3 \mathrm{~h}$ later we exposed the snails to $\mathrm{Q}$ for $1 \mathrm{~h}$ (Figure 4B). These snails then were trained with a $0.5 \mathrm{~h}$ training session (T0) and were tested for LTM 24h later (i.e., T24). The sequential presentation of the single poke and then $\mathrm{Q}$ exposure resulted in LTM. That is, the number of attempted pneumostome openings in $\mathrm{T} 24$ was significantly less than in $\mathrm{T} 0(\mathrm{t}=2.84, \mathrm{df}=9 ; \mathrm{p}=$ 0.02). Thus, the 'single-poke' procedure and Q-exposure $3 \mathrm{~h}$ later was sufficient to cause LTM formation following a $0.5 \mathrm{~h}$ training session $20 \mathrm{~h}$ later. Not shown here, are control experiments where the vehicle is used rather than $\mathrm{Q}$ along with the singlepoke procedure; in all cases enhanced LTM formation was not observed. 


\section{Discussion}

347

348

349

350

351

352

353

354

355

356

357

358

359

360

361

362

363

364

365

366

367

368

369

370

371

372

373

374

375

This study tested the hypothesis that Q-exposure during critical periods of memory formation enhanced LTM formation following operant conditioning of aerial respiratory behaviour. Thus, Q-exposure $3 \mathrm{~h}$ before or after the different phases of learning and memory (e.g., consolidation and recall) lead to enhance LTM formation. In addition, Q-exposure improved LTM formation following the 'single poke' procedure. These data are all consistent with Q-exposure upregulating LymCREB1 which then synergistically interacts with the other molecular events necessary to form LTM. Q-exposure has previously been shown to act in the snails' nervous system to both block the up-regulation of heat shock proteins (HSPs) following a heat shock and to up-regulate LymCREB1 (Foster et al., 2015; Sunada et al., 2016; Rivi et al., 2021a; Batabyal et al., 2021). Since LymCREB1 plays a key role in conditioned taste aversion memory formation in Lymnaea (Sadamoto et al., 2004), our data extend those findings to include memory formation following operant conditioning of aerial respiratory behaviour. Here we showed that Q-exposure alters four different phases of memory: 1) acquisition (i.e., a learning event), 2) consolidation processes after acquisition, 3) memory recall, and 4) memory reconsolidation. In all these memory phases Q-exposure enhanced LTM persistence.

Memory is stored in specific neural networks termed 'memory engrams' (Semon, 1921) that can be modified by factors such as stress, increased training and, in the data shown here, the exposure to certain bio-active products such as Q. While not examined here, we hypothesize that Q-exposure alters the activity of an identified neuron, RPeD1 (Right Pedal Dorsal 1), known to be a necessary site for LTM formation, extinction, and reconsolidation (Lukowiak et al., 2006; Sangha et al., 2005; Sangha et al., 2003a,b; Sangha, Scheibenstock, and Lukowiak, 2003; Scheibenstock et al., 2002). Previously, it has been shown that predator detection (using crayfish effluent - CE) alters the behaviour of this neuron leading to enhanced LTM formation (Orr and Lukowiak, 2008). However, for that to occur snails had to be trained in CE. The exposure to $\mathrm{CE} 1 \mathrm{~h}$ before or $1 \mathrm{~h}$ after a single $0.5 \mathrm{~h}$ did not cause LTM enhancement. In a similar vein, another bio-active substance, epicatechin, also had to 
376 be experienced either during or immediately after training to cause LTM enhancement

377 (Fernell et al., 2016)

Our working hypothesis was that Q-exposure, which causes an up-regulation of LymCREB1 3 hours after exposure (Batabyal et al., 2021), results in enhanced LTM formation when Q-exposure occurs within 3 hours of the different phases of learning and memory formation. That is, boosting LymCREBI activity during the 3-hour window prior to or after the single $0.5 \mathrm{~h}$ operant conditioning training session may amplify the on-going and necessary molecular processes that underlie LTM. The experiments reported here were all designed to test this hypothesis. Our data also add to our knowledge that bio-active, naturally occurring substances, such as Q, can alter cognitive ability (e.g., enhanced LTM formation). Finally, the data also illustrate the advantages of using our model system in gaining an understanding of how substances, such as Q, alter cognition. Q, as well as many other compounds (e.g., epicatechin), easily penetrate through the integument of the snail and, because snails have an open circulatory system, can easily and quickly reach the CNS (Fruson et al., 2012; Rivi et al., 2021b, Rivi et al., 2020).

The highly conserved CREB gene and CREB-like proteins have been characterized in Lymnaea nervous system (Frank and Greenberg, 1994) Ribeiro et al., 2003; Sadamoto et al., 2004) and it has been demonstrated that the conditioned taste aversion (CTA) training increased LymCREB1 expression levels (Sadamoto et al., 2010). Moreover, the levels of phosphorylated CREB1 are also increased following appetitive classical conditioning of feeding behaviour (Ribeiro et al., 2003). In particular, in appetitive conditioning studies it was demonstrated that between $10 \mathrm{~min}$ and $1 \mathrm{~h}$ after training, many translational-dependent processes are activated to form ITM. While ITM only requires the synthesis of new proteins from pre-existing mRNA transcripts, LTM is 403 dependent on altered gene activity, new protein synthesis and transport of the 404 protein(s) to the site of plasticity (Braun and Lukowiak, 2011; Lukowiak et al., 2000; 405 Rosenzweig et al., 1993). ITM and LTM are independent but interrelated events 406 which occur in parallel and has specific temporal phases and transition periods (Marra 
407

408

409

410

411

412

413

414

415

416

417

418

419

420

421

422

423

424

425

426

427

428

429

430

431

432

433

434

435

436

437

et al., 2013). As CREB1 is a regulator of mRNA transcription, it most likely does not play a necessary role in ITM formation but does so for LTM formation (Sadamoto et al., 2004). Studies in Drosophila and rodent models also demonstrate that neurons with higher CREB levels are preferentially recruited for LTM engrams as de novo transcription and translation is required during formation and consolidation of LTM (Han et al., 2007; Miyashita et al., 2018).

In the $\mathrm{W}$-strain of Lymnaea used here a $0.5 \mathrm{~h}$ training session is only capable of causing a memory that persists for approximately $3 \mathrm{~h}$ and this has been termed intermediate-term memory (ITM, Sangha et al., 2003a,b). However, Parvez et al., (2005, 2006) found that there was a residual memory trace $24 \mathrm{~h}$ after training, even though the LTM phenotype was absent. Thus, it was apparent to us that we could ascertain whether the exposure to $\mathrm{Q} 3 \mathrm{~h}$ before or after this period caused LTM enhancement when combined with the presentation of a stimulus associated with learning (i.e., the single poke procedure). As we showed here, exposing snails to $\mathrm{Q}$ $20 \mathrm{~h}$ after a $0.5 \mathrm{~h}$ training session was sufficient for the single-poke procedure performed $3 \mathrm{~h}$ later to cause LTM formation when tested after T0. Similarly, we showed that using the single-poke procedure $24 \mathrm{~h}$ after the initial $0.5 \mathrm{~h}$ training session and then $3 \mathrm{~h}$ later exposing snails to $\mathrm{Q}$ resulted in a LTM when tested $48 \mathrm{~h}$ after the initial training session (i.e., T0). Both the consolidation and reconsolidation processes of LTM in our model system, as well as in vertebrates, have been shown to be dependent on altered gene activity (i.e., transcription) and de novo protein synthesis (i.e., translation) (Anokhin et al., 2002; Debiec et al., 2002; Judge and Quartermain, 1982; Kida et al., 2002; Milekic and Alberini, 2002; Nader and Einarsson, 2010). Moreover, there are several lines of evidence implying that memory consolidation and reconsolidation use similar molecular pathways that converge on the activation of CREB1 (Alberini, 2011; McKenzie and Eichenbaum, 2011; Nader and Einarsson, 2010; Tronson and Taylor, 2007).

Together these data are consistent with our hypothesis that $\mathrm{Q}$, which induces an upregulation of $L y m C R E B 1$, interacts synergistically with the molecular processes that underlie LTM formation, consolidation, and reconsolidation. Thus, Q-exposure, 
in essence, boosts those processes if the boost occurs within a specific "window of opportunity'. Outside of that window, an enhancement of LTM formation is not observed.

$$
\text { We further showed, using the single-poke procedure, that the exposure to } \mathrm{Q} 3 \mathrm{~h} \text { before }
$$
or after the single poke procedure enabled a $0.5 \mathrm{~h}$ training session, given some $20 \mathrm{~h}$ after the Q-exposure combined with the single-poke procedure, to result in LTM formation. These data suggest that the Q-induced upregulation of LymCREB1 persists for sufficient time, such that the one $0.5 \mathrm{~h}$ training session became capable of inducing the molecular changes necessary for LTM formation. We plan to investigate this in detail in our future experiments.

Our findings reported here on the enhancement of LTM formation with Q-exposure are also consistent with our recent findings on configural learning in Lymnaea (Batabyal et al., 2021). In that study, Q-exposure $3 \mathrm{~h}$ prior to, immediately before or $3 \mathrm{~h}$ following configural learning training, enhanced LTM formation. Usually, the configural learning procedure only results in memory persisting for $3 \mathrm{~h}$ (i.e., ITM) but following Q-exposure an LTM was formed that persisted in some cases for $48 \mathrm{~h}$ (Batabyal et al., 2021).

Previous studies demonstrated that a $0.5 \mathrm{~h}$ is sufficient to produce an ITM trace lasting 3h, which is dependent on new protein synthesis (Braun and Lukowiak, 2011; Lukowiak et al., 2000; Sangha et al., 2003a,b). It is at this $3 \mathrm{~h}$ post training time, in appetitive food conditioning, that Lymnaea show a transition from 'late-ITM' to LTM that requires RNA synthesis (Marra et al., 2013). During the $3 \mathrm{~h}$ interval between training and Q-exposure the molecular machinery required for ITM to be converted to LTM is induced by Q via upregulation of LymCREB1. These data are consistent with previous studies from both invertebrates and vertebrates showing the key role of CREB1 in LTM formation and consolidation after various learning paradigms (Alberini, 2011; Sangha, Scheibenstock, and Lukowiak, 2003). We conclude that Q- 
exposure $3 \mathrm{~h}$ before or after training, while acting on different mnemonic phases (i.e., memory formation and consolidation, respectively), enhances the persistence of LTM in Lymnaea.

Our data are also consistent with the hypothesis that dietary sources of Q could improve cognitive ability (Finkbeiner et al., 1997; Kida, 2012; Silva et al., 1998; Suzuki et al., 2011). Further, our data illustrate that Lymnaea is a suitable model to elucidate neuronal and molecular mechanisms induced by Q-exposure during the different phases in the process of transforming learning into memory and its recall. We hypothesize that LymCREBI activation is differentially involved and regulated depending on the time of Q-exposure. Other studies suggested that flavonoids may modulate kinase activity [e.g., mitogen-activated protein kinase (MAPK) cascade] and signalling cascades lying downstream of these kinases (Spencer, 2007). The protein kinase/MAPK signalling cascades have been shown to be necessary for both ITM and LTM formation in Lymnaea (Ribeiro et al., 2003). Therefore, alteration of protein kinase activity following Q-exposure may potentially be the mechanism by which memory formation is enhanced in Lymnaea.

Findings presented here provide the groundwork for future molecular analysis of how Q-exposure acts at the neuronal level and the mechanisms involved in the alterations to memory formation, storage and, recall, paving the way for interesting translational neuroscience studies. Our current data provides the first support for Q-modulated enhancement of cognitive function in an invertebrate model after an operant conditioning procedure. Thus, strengthening the case for Lymnaea as a model for translational neuroscience (Rivi et al., 2021b, Fodor et al., 2020).

Acknowledgements: We would like to thank Diana Kagan, Bevin Wiley, and David Chau for the discussions during the research.

Funding: Funding was provided by the Natural Sciences and Engineering Research Council of Canada (NSERC) to KL. 
498 Competing interests: We have no competing interests.

499

500 Author's contributions: VR, AB, and KL conceptualised and designed study. VR

501 performed behavioural data collection, analysis and writing first draft. AB, CB,

502 JMCB, and FT critically revised manuscript. KL coordinated study, provided funding,

503 and critically revised manuscript. All authors take responsibility of the data provided

504 and consent to the publication of the manuscript.

505 
506

507

508

509

510

511

512

513

514

515

516

517

518

519

520

521

522

523

524

525

526

527

528

529

530

531

532

533

534

535

536

\section{References}

Ahmad, S., Ullah, F., Ayaz, M., Sadiq, A. and Imran, M. (2015). Antioxidant and anticholinesterase investigations of Rumex hastatus D. Don: Potential effectiveness in oxidative stress and neurological disorders. Biological Research, 48(1), 20. https://doi.org/10.1186/s40659-015-0010-2

Alberini, C. M. (2009). Transcription Factors in Long-Term Memory and Synaptic Plasticity. Physiological Reviews, 89(1). https://doi.org/10.1152/physrev.00017.2008

Alberini, C. M. (2011). The Role of Reconsolidation and the Dynamic Process of Long-Term Memory Formation and Storage. Frontiers in Behavioural Neuroscience, 5. https://doi.org/10.3389/fnbeh.2011.00012

Anokhin, K. V., Tiunova, A. A. and Rose, S. P. R. (2002). Reminder effects reconsolidation or retrieval deficit? Pharmacological dissection with protein synthesis inhibitors following reminder for a passive-avoidance task in young chicks: Memory consolidation and reminder effects in chicks. European Journal of Neuroscience, 15(11), 1759-1765. https://doi.org/10.1046/j.14609568.2002.02023.x

Ansari, M. A., Abdul, H. M., Joshi, G., Opii, W. O. and Butterfield, D. A. (2009). Protective effect of quercetin in primary neurons against $A \beta(1-42)$ : Relevance to Alzheimer's disease. The Journal of Nutritional Biochemistry, 20(4), 269275. https://doi.org/10.1016/j.jnutbio.2008.03.002

Ayaz, M., Sadiq, A., Junaid, M., Ullah, F., Ovais, M., Ullah, I., Ahmed, J. and Shahid, M. (2019). Flavonoids as Prospective Neuroprotectants and Their Therapeutic Propensity in Aging Associated Neurological Disorders. Frontiers in Aging Neuroscience, 11. https://doi.org/10.3389/fnagi.2019.00155

Bakoyiannis, I., Daskalopoulou, A., Pergialiotis, V. and Perrea, D. (2019). Phytochemicals and cognitive health: Are flavonoids doing the trick? Biomedicine and Pharmacotherapy, 109, 1488-1497. https://doi.org/10.1016/j.biopha.2018.10.086

Barco, A., Pittenger, C. and Kandel, E. R. (2003). CREB, memory enhancement and the treatment of memory disorders: Promises, pitfalls and prospects. Expert 
537

538

539

540

541

542

543

544

545

546

547

548

549

550

551

552

553

554

555

556

557

558

559

560

561

562

563

564

565

566

567

568

Opinion on Therapeutic Targets, 7(1), 101-114. https://doi.org/10.1517/14728222.7.1.101

Batabyal, A., Rivi, V., Benatti, C., Blom, J. M. C., and Lukowiak, K. (2021). Long term memory of configural learning is enhanced via CREB upregulation by the flavonoid Quercetin in Lymnaea stagnalis. Journal of Experimental Biology. J Exp Biol jeb.242761. https://doi.org/10.1242/jeb.242761

Bhutada, P., Mundhada, Y., Bansod, K., Bhutada, C., Tawari, S., Dixit, P., and Mundhada, D. (2010). Ameliorative effect of quercetin on memory dysfunction in streptozotocin-induced diabetic rats. Neurobiology of Learning and Memory, 94(3), 293-302. https://doi.org/10.1016/j.nlm.2010.06.008

Bisaz, R., Travaglia, A., and Alberini, C. M. (2014). The neurobiological bases of memory formation: From physiological conditions to psychopathology. Psychopathology, 47(6), 347-356. https://doi.org/10.1159/000363702

Bozon, B., Kelly, Á., Josselyn, S. A., Silva, A. J., Davis, S. and Laroche, S. (2003). MAPK, CREB and zif268 are all required for the consolidation of recognition memory. Philosophical Transactions of the Royal Society of London. Series B: Biological Sciences, 358(1432), 805-814. https://doi.org/10.1098/rstb.2002.1224

Braun, M. H. and Lukowiak, K. (2011). Intermediate and long-term memory are different at the neuronal level in Lymnaea stagnalis (L.). Neurobiology of Learning and Memory, 96(2), 403-416. https://doi.org/10.1016/j.nlm.2011.06.016

Brem, A.-K., Ran, K. and Pascual-Leone, A. (2013). Learning and memory. Handbook of Clinical Neurology, 116, 693-737. https://doi.org/10.1016/B9780-444-53497-2.00055-3

Broman-Fulks, J. J., Canu, W. H., Trout, K. L. and Nieman, D. C. (2012). The effects of quercetin supplementation on cognitive functioning in a community sample: A randomized, placebo-controlled trial. Therapeutic Advances in Psychopharmacology, $2(4)$

$131-138$. https://doi.org/10.1177/2045125312445894

Conte, C., Herdegen, S., Kamal, S., Patel, J., Patel, U., Perez, L., Rivota, M., CalinJageman, R. J. and Calin-Jageman, I. E. (2017). Transcriptional correlates of 
569

570

571

572

573

574

575

576

577

578

579

580

581

582

583

584

585

586

587

588

589

590

591

592

593

594

595

596

597

598

599

600

memory maintenance following long-term sensitization of Aplysia californica.

Learning and Memory (Cold Spring Harbor, N.Y.), 24(10), 502-515. https://doi.org/10.1101/1m.045450.117

Cushnie, T. P. T. and Lamb, A. J. (2005). Antimicrobial activity of flavonoids. International Journal of Antimicrobial Agents, 26(5), 343-356. https://doi.org/10.1016/j.ijantimicag.2005.09.002

Dalesman, S. and Rundle, S. (2010). Influence of rearing and experimental temperatures on predator avoidance behaviour in a freshwater pulmonate snail. Freshwater Biology, 55, 2107-2113. https://doi.org/10.1111/j.13652427.2010.02470.x

Davis, R. L. (2011). Traces of Drosophila Memory. Neuron, 70(1), 8-19. https://doi.org/10.1016/j.neuron.2011.03.012

Debiec, J., LeDoux, J. E. and Nader, K. (2002). Cellular and Systems Reconsolidation in the Hippocampus. Neuron, 36(3), 527-538. https://doi.org/10.1016/S08966273(02)01001-2

Eggler, A. L., Gay, K. A. and Mesecar, A. D. (2008). Molecular mechanisms of natural products in chemoprevention: Induction of cytoprotective enzymes by Nrf2. Molecular Nutrition and Food Research. https://doi.org/10.1002/mnfr.200700249

Fernell, M., Swinton, C., and Lukowiak, K. (2016). Epicatechin, a component of dark chocolate, enhances memory formation if applied during the memory consolidation period. Communicative and Integrative Biology, 9(4), e1205772. https://doi.org/10.1080/19420889.2016.1205772

Finkbeiner, S., Tavazoie, S. F., Maloratsky, A., Jacobs, K. M., Harris, K. M. and Greenberg, M. E. (1997). CREB: A Major Mediator of Neuronal Neurotrophin Responses. Neuron, 19(5), 1031-1047. https://doi.org/10.1016/S08966273(00)80395-5

Fodor, I., Hussein, A. A., Benjamin, P. R., Koene, J. M., and Pirger, Z. (2020). The unlimited potential of the great pond snail, Lymnaea stagnalis. ELife, 9, e56962. https://doi.org/10.7554/eLife.56962

Foster, N. L., Lukowiak, K. and Henry, T. B. (2015). Time-related expression profiles for heat shock protein gene transcripts (HSP40, HSP70) in the central nervous 
601

602

603

604

605

606

607

608

609

610

611

612

613

614

615

616

617

618

619

620

621

622

623

624

625

626

627

628

629

630

system of Lymnaea stagnalis exposed to thermal stress. Communicagive and integrative biology, 8(3), e1040954. https://doi.org/10.1080/19420889.2015.1040954

Frank, D. A. and Greenberg, M. E. (1994). CREB: A mediator of long-term memory from mollusks to mammals. Cell, 79(1), 5-8. https://doi.org/10.1016/00928674(94)90394-8

Fruson, L., Dalesman, S. and Lukowiak, K. (2012). A flavonol present in cocoa [()epicatechin] enhances snail memory. Journal of Experimental Biology, 215(20), 3566-3576. https://doi.org/10.1242/jeb.070300

Haleagrahara, N., Siew, C. J., Mitra, N. K. and Kumari, M. (2011). Neuroprotective effect of bioflavonoid quercetin in 6-hydroxydopamine-induced oxidative stress biomarkers in the rat striatum. Neuroscience Letters, 500(2), 139-143. https://doi.org/10.1016/j.neulet.2011.06.021

Han, J.-H., Kushner, S. A., Yiu, A. P., Cole, C. J., Matynia, A., Brown, R. A., Neve, R. L., Guzowski, J. F., Silva, A. J. and Josselyn, S. A. (2007). Neuronal Competition and Selection During Memory Formation. Science, 316(5823), 457-460. https://doi.org/10.1126/science.1139438

Havsteen, B. H. (2002). The biochemistry and medical significance of the flavonoids. Pharmacology and Therapeutics, 96(2-3), 67-202. https://doi.org/10.1016/s0163-7258(02)00298-X

Hawkins, R. D., Kandel, E. R. and Bailey, C. H. (2006). Molecular mechanisms of memory storage in Aplysia. The Biological Bulletin, 210(3), 174-191. https://doi.org/10.2307/4134556

Isabel, G., Pascual, A. and Preat, T. (2004). Exclusive consolidated memory phases in Drosophila. Science (New York, N.Y.), 304(5673), 1024-1027. https://doi.org/10.1126/science.1094932

Jayasena, T., Poljak, A., Smythe, G., Braidy, N., Münch, G. and Sachdev, P. (2013). The role of polyphenols in the modulation of sirtuins and other pathways involved in Alzheimer's disease. Ageing Research Reviews, 12(4), 867-883. https://doi.org/10.1016/j.arr.2013.06.003 
631 Judge, M. and Quartermain, D. (1982). Characteristics of retrograde amnesia

632

633

634

635

636

637

638

639

640

641

642

643

644

645

646

647

648

649

650

651

652

653

654

655

656

657

658

659

660

661

662 following reactivation of memory in mice. Physiology and Behaviour, 28(4), 585-590. https://doi.org/10.1016/0031-9384(82)90034-8

Kandel, E. R., Dudai, Y. and Mayford, M. R. (2014). The molecular and systems biology of memory. Cell, 157(1), 163-186. https://doi.org/10.1016/j.cell.2014.03.001

Karimipour, M., Rahbarghazi, R., Tayefi, H., Shimia, M., Ghanadian, M., Mahmoudi, J. and Bagheri, H. S. (2019). Quercetin promotes learning and memory performance concomitantly with neural stem/progenitor cell proliferation and neurogenesis in the adult rat dentate gyrus. International Journal of Developmental Neuroscience: The Official Journal of the International Society for Developmental Neuroscience, 74, 18-26. https://doi.org/10.1016/j.ijdevneu.2019.02.005

Karnik, V., Dalesman, S. and Lukowiak, K. (2012). Input from a chemosensory organ, the osphradium, does not mediate aerial respiration in Lymnaea stagnalis. Aquatic Biology, 15(2), 167-173. https://doi.org/10.3354/ab00416

Khan, H., Marya, Amin, S., Kamal, M. A., and Patel, S. (2018). Flavonoids as acetylcholinesterase inhibitors: Current therapeutic standing and future prospects. Biomedicine and Pharmacotherapy, 101, 860-870. https://doi.org/10.1016/j.biopha.2018.03.007

Kida, S. (2012). A Functional Role for CREB as a Positive Regulator of Memory Formation and LTP. Experimental Neurobiology, 21(4), 136-140. https://doi.org/10.5607/en.2012.21.4.136

Kida, S., Josselyn, S. A., de Ortiz, S. P., Kogan, J. H., Chevere, I., Masushige, S., and Silva, A. J. (2002). CREB required for the stability of new and reactivated fear memories. Nature Neuroscience, 5(4), 348-355. https://doi.org/10.1038/nn819

Knezevic, B., Dalesman, S., Karnik, V., Byzitter, J., and Lukowiak, K. (2011). Low external environmental calcium levels prevent forgetting in Lymnaea. Journal of Experimental Biology, 214(12), 2118-2124. https://doi.org/10.1242/jeb.054635

Knezevic, B., and Lukowiak, K. (2014). The flavonol epicatechin reverses the suppressive effects of a stressor on long-term memory formation. Journal of 
663

664

665

666

667

668

669

670

671

672

673

674

675

676

677

678

679

680

681

682

683

684

685

686

687

688

689

690

691

692

693

694

Experimental Biology,

217(22),

4004-4009. https://doi.org/10.1242/jeb.110726

Kong, A.-N. T., Yu, R., Chen, C., Mandlekar, S., and Primiano, T. (2000). Signal transduction events elicited by natural products: Role of MAPK and caspase pathways in homeostatic response and induction of apoptosis. Archives of Pharmacal Research, 23(1), 1-16. https://doi.org/10.1007/BF02976458

Letenneur, L., Proust-Lima, C., Le Gouge, A., Dartigues, J., and Barberger-Gateau, P. (2007). Flavonoid Intake and Cognitive Decline over a 10-Year Period. American Journal of Epidemiology, 165(12), 1364-1371. https://doi.org/10.1093/aje/kwm036

Lukowiak, K., Ringseis, E., Spencer, G., Wildering, W., and Syed, N. (1996). Operant conditioning of aerial respiratory behaviour in Lymnaea stagnalis. The Journal of Experimental Biology, 199(Pt 3), 683-691.

Lukowiak, K., Adatia, N., Krygier, D. and Syed, N. (2000). Operant Conditioning in Lymnaea: Evidence for Intermediate- and Long-term Memory. Learning and Memory, 7(3), 140-150.

Lukowiak, K., Martens, K., Orr, M., Parvez, K., Rosenegger, D. and Sangha, S. (2006). Modulation of aerial respiratory behaviour in a pond snail. Respiratory Physiology and Neurobiology, 154(1-2), 61-72. https://doi.org/10.1016/j.resp.2006.02.009

Lukowiak, K., Orr, M., de Caigny, P., Lukowiak, K. S., Rosenegger, D., Han, J. I. and Dalesman, S. (2010). Ecologically relevant stressors modify long-term memory formation in a model system. Behavioural Brain Research, 214(1), 18-24. https://doi.org/10.1016/j.bbr.2010.05.011

Macready, A. L., Kennedy, O. B., Ellis, J. A., Williams, C. M., Spencer, J. P. E. and Butler, L. T. (2009). Flavonoids and cognitive function: A review of human randomized controlled trial studies and recommendations for future studies. Genes and Nutrition, 4(4), 227-242. https://doi.org/10.1007/s12263-0090135-4

Manach, C., Scalbert, A., Morand, C., Rémésy, C. and Jiménez, L. (2004). Polyphenols: Food sources and bioavailability. The American Journal of Clinical Nutrition, 79(5), 727-747. https://doi.org/10.1093/ajcn/79.5.727 
695

696

697

698

699

700

701

702

703

704

705

706

707

708

709

710

711

712

713

714

715

716

717

718

719

720

721

722

723

Manach, C., Williamson, G., Morand, C., Scalbert, A. and Rémésy, C. (2005). Bioavailability and bioefficacy of polyphenols in humans. I. Review of 97 bioavailability studies. The American Journal of Clinical Nutrition, 81(1), 230S-242S. https://doi.org/10.1093/ajen/81.1.230S

Mandel, S. and Youdim, M. B. H. (2004). Catechin polyphenols: Neurodegeneration and neuroprotection in neurodegenerative diseases. Free Radical Biology and Medicine, $37(3)$, 304-317. https://doi.org/10.1016/j.freeradbiomed.2004.04.012

Marra, V., O'Shea, M., Benjamin, P. and Kemenes, I (2013) Susceptibility of memory consolidation during lapses in recall. Nat Comm 4:1578

Mastroiacovo, D., Kwik-Uribe, C., Grassi, D., Necozione, S., Raffaele, A., Pistacchio, L., Righetti, R., Bocale, R., Lechiara, M. C., Marini, C. et al., (2015). Cocoa flavanol consumption improves cognitive function, blood pressure control, and metabolic profile in elderly subjects: The Cocoa, Cognition, and Aging (CoCoA) Study - a randomized controlled trial. The American Journal of Clinical Nutrition, 101(3), 538-548. https://doi.org/10.3945/ajen.114.092189

Matsuno, M., Horiuchi, J., Yuasa, Y., Ofusa, K., Miyashita, T., Masuda, T. and Saitoe, M. (2015). Long-Term Memory Formation in Drosophila Requires Training-Dependent Glial Transcription. The Journal of Neuroscience, 35(14), 5557-5565. https://doi.org/10.1523/JNEUROSCI.3865-14.2015

McKenzie, S., and Eichenbaum, H. (2011). Consolidation and reconsolidation: Two lives of memories? Neuron, 71(2), 224-233. https://doi.org/10.1016/j.neuron.2011.06.037

Milekic, M. H. and Alberini, C. M. (2002). Temporally Graded Requirement for Protein Synthesis following Memory Reactivation. Neuron, 36(3), 521-525. https://doi.org/10.1016/S0896-6273(02)00976-5

Milner, B., Squire, L. R. and Kandel, E. R. (1998). Cognitive neuroscience and the study of memory. Neuron, 20(3), 445-468. https://doi.org/10.1016/s08966273(00)80987-3 
Miyashita, T., Kikuchi, E., Horiuchi, J. and Saitoe, M. (2018). Long-Term Memory Engram Cells Are Established by c-Fos/CREB Transcriptional Cycling. Cell Reports, 25(10), 2716-2728.e3. https://doi.org/10.1016/j.celrep.2018.11.022

Morel, I., Lescoat, G., Cogrel, P., Sergent, O., Pasdeloup, N., Brissot, P., Cillard, P., and Cillard, J. (1993). Antioxidant and iron-chelating activities of the flavonoids catechin, quercetin and diosmetin on iron-loaded rat hepatocyte $\begin{array}{llll}\text { cultures. } & \text { Biochemical } & \text { Pharmacology, } & \text { 45(1), }\end{array}$ https://doi.org/10.1016/0006-2952(93)90371-3

Nader K, Schafe GE, LeDoux JE (2000) Fear memories require protein synthesis in the amygdala for reconsolidation after retrieval. Nature 406:722-726.

Nader, K., and Einarsson, E. Ö. (2010). Memory reconsolidation: An update. Annals of the New York Academy of Sciences, 1191(1), 27-41. https://doi.org/10.1111/j.1749-6632.2010.05443.x

Nakagawa, T., Itoh, M., Ohta, K., Hayashi, Y., Hayakawa, M., Yamada, Y., Akanabe, H., Chikaishi, T., Nakagawa, K., Itoh, Y., Muro, T., Yanagida, D., Nakabayashi, R., Mori, T., Saito, K., Ohzawa, K., Suzuki, C., Li, S., Ueda, M., ... Inuzuka, T. (2016). Improvement of memory recall by quercetin in rodent contextual fear conditioning and human early-stage Alzheimer's disease patients.

NeuroReport,

$27(9)$,

671-676. https://doi.org/10.1097/WNR.0000000000000594

Orr, M. V., and Lukowiak, K. (2008). Electrophysiological and Behavioural Evidence Demonstrating That Predator Detection Alters Adaptive Behaviours in the Snail Lymnaea. Journal of Neuroscience, 28(11), 2726-2734. https://doi.org/10.1523/JNEUROSCI.5132-07.2008

Parvez, K. (2005). Boosting intermediate-term into long-term memory. Journal of Experimental Biology, 208(8), 1525-1536. https://doi.org/10.1242/jeb.01545

Parvez, Kashif, Moisseev, V., and Lukowiak, K. (2006). A context-specific single contingent-reinforcing stimulus boosts intermediate-term memory into longterm memory. European Journal of Neuroscience, 24(2), 606-616. https://doi.org/10.1111/j.1460-9568.2006.04952.x 
Philips, G. T., Tzvetkova, E. I., Marinesco, S., and Carew, T. J. (2006). Latent memory for sensitization in Aplysia. Learning and Memory, 13(2), 224-229. https://doi.org/10.1101/lm.111506

Reznichenko, L., Amit, T., Zheng, H., Avramovich-Tirosh, Y., Youdim, M. B. H., and Mandel, S. (2006). Reduction of iron-regulated amyloid precursor protein and $\beta$-amyloid peptide by (-)-epigallocatechin-3-gallate in cell cultures: Implications for iron chelation in Alzheimer's disease: Iron-mediated reduction of amyloid precursor protein. Journal of Neurochemistry, 97(2), 527-536. https://doi.org/10.1111/j.1471-4159.2006.03770.x

Ribeiro, M. J., Serfozo, Z., Papp, A., Kemenes, I., O’Shea, M., Yin, J. C. P., Benjamin, P. R., and Kemenes, G. (2003). Cyclic AMP response elementbinding (CREB)-like proteins in a molluscan brain: Cellular localization and learning-induced phosphorylation. The European Journal of Neuroscience, 18(5), 1223-1234. https://doi.org/10.1046/j.1460-9568.2003.02856.x

Rivi, V., Benatti, C., Colliva, C., Radighieri, G., Brunello, N., Tascedda, F., and Blom, J. M. C. (2020). Lymnaea stagnalis as model for translational neuroscience research: From pond to bench. Neuroscience and Biobehavioural Reviews, 108, 602-616. https://doi.org/10.1016/j.neubiorev.2019.11.020

Rivi, V., Benatti, C., Lukowiak, K., Colliva, C., Alboni, S., Tascedda, F., and Blom, J. M. C. (2021b). What can we teach Lymnaea and what can Lymnaea teach us? Biological Reviews, brv.12716. https://doi.org/10.1111/brv.12716

Rivi, V., Batabyal, A., Benatti, C., Blom, J. M. C., and Lukowiak, K. (2021a). To eat or not to eat: A Garcia effect in pond snails (Lymnaea stagnalis). Journal of Comparative Physiology A. Accepted

Robak, J., and Gryglewski, R. J. (1988). Flavonoids are scavengers of superoxide anions. Biochemical Pharmacology, 37(5), 837-841. https://doi.org/10.1016/0006-2952(88)90169-4

Rosenzweig, M. R., Bennett, E. L., Colombo, P. J., Lee, D. W., and Serrano, P. A. (1993). Short-term, intermediate-term, and long-term memories. Behavioural Brain Research, 57(2), 193-198. https://doi.org/10.1016/01664328(93)90135-D 
Sadamoto, H., Kitahashi, T., Fujito, Y., and Ito, E. (2010). Learning-dependent gene expression of CREB1 isoforms in the molluscan brain. Frontiers in Behavioural Neuroscience, 4. https://doi.org/10.3389/fnbeh.2010.00025

Sadamoto, H., Sato, H., Kobayashi, S., Murakami, J., Aonuma, H., Ando, H., Fujito, Y., Hamano, K., Awaji, M., Lukowiak, K., Urano, A., and Ito, E. (2004). CREB in the Pond Snail Lymnaea stagnalis: Cloning, Gene Expression and Function in Identifiable Neurons of the Central Nervous System. Journal of Neurobiology, 58, 455-466. https://doi.org/10.1002/neu.10296

Sangha, S., Scheibenstock, A. McComb, C. and Lukowiak, K. (2003a). Intermediate and long-term memories of associative learning are differentially affected by transcription versus translation blockers in Lymnaea. Journal of Experimental Biology, 206(10), 1605-1613. https://doi.org/10.1242/jeb.00301

Sangha, S., Morrow, R., Smyth, K., Cooke, R., and Lukowiak, K. (2003b). Cooling blocks ITM and LTM formation and preserves memory. Neurobiology of Learning and Memory, 80(2), 130-139. https://doi.org/10.1016/S10747427(03)00065-0

Sangha, S., Scheibenstock, A., and Lukowiak, K. (2003c). Reconsolidation of a LongTerm Memory in Lymnaea Requires New Protein and RNA Synthesis and the Soma of Right Pedal Dorsal 1. The Journal of Neuroscience, 23(22), 80348040. https://doi.org/10.1523/JNEUROSCI.23-22-08034.2003

Sangha, S., Scheibenstock, A., Martens, K., Varshney, N., Cooke, R., and Lukowiak, K. (2005). Impairing Forgetting by Preventing New Learning and Memory. Behavioural Neuroscience, 119(3), 787-796. https://doi.org/10.1037/07357044.119.3.787

Scheibenstock, A., Krygier, D., Haque, Z., Syed, N., and Lukowiak, K. (2002). The Soma of RPeD1 Must Be Present for Long-Term Memory Formation of Associative Learning in Lymnaea. Journal of Neurophysiology, 88(4), 15841591. https://doi.org/10.1152/jn.2002.88.4.1584

Schroeter, H., Bahia, P., Spencer, J. P. E., Sheppard, O., Rattray, M., Cadenas, E., Rice-Evans, C., and Williams, R. J. (2007). (-)Epicatechin stimulates ERKdependent cyclic AMP response element activity and up-regulates GluR2 in 
cortical neurons. Journal of Neurochemistry, 101(6), 1596-1606. https://doi.org/10.1111/j.1471-4159.2006.04434.x

Semon R. (1921) The mneme. London: Allen, Unwin.

Silva, A. J., Kogan, J. H., Frankland, P. W., and Kida, S. (1998). CREB and memory. Annual Review of Neuroscience, 21, 127-148. https://doi.org/10.1146/annurev.neuro.21.1.127

Socci, V., Tempesta, D., Desideri, G., De Gennaro, L., and Ferrara, M. (2017). Enhancing Human Cognition with Cocoa Flavonoids. Frontiers in Nutrition, 4, 19. https://doi.org/10.3389/fnut.2017.00019

Spencer, J. P. E. (2007). The interactions of flavonoids within neuronal signalling pathways. Genes and Nutrition, 2(3), 257-273. https://doi.org/10.1007/s12263-007-0056-Z

Spencer, J. P. E. (2008). Flavonoids: Modulators of brain function? British Journal of Nutrition, 99(E-S1), ES60-ES77. https://doi.org/10.1017/S0007114508965776

Spencer, J. P. E., Rice-Evans, C., and Williams, R. J. (2003). Modulation of Prosurvival Akt/Protein Kinase B and ERK1/2 Signaling Cascades by Quercetin and Its in Vivo Metabolites Underlie Their Action on Neuronal Viability. Journal of Biological Chemistry, 278(37), 34783-34793. https://doi.org/10.1074/jbc.M305063200

Squire, L. R., Genzel, L., Wixted, J. T., and Morris, R. G. (2015). Memory Consolidation. Cold Spring Harbor Perspectives in Biology, 7(8). https://doi.org/10.1101/cshperspect.a021766

Stevens, C. F. (1994). CREB and memory consolidation. Neuron, 13(4), 769-770. https://doi.org/10.1016/0896-6273(94)90244-5

Sunada, H., Totani, Y., Nakamura, R., Sakakibara, M., Lukowiak, K., and Ito, E. (2017). Two Strains of Lymnaea stagnalis and the Progeny from Their Mating Display Differential Memory-Forming Ability on Associative Learning Tasks. Frontiers in Behavioural $\quad 11$. https://doi.org/10.3389/fnbeh.2017.00161

Suzuki, A., Fukushima, H., Mukawa, T., Toyoda, H., Wu, L.-J., Zhao, M.-G., Xu, H., Shang, Y., Endoh, K., Iwamoto, T., Mamiya, N., Okano, E., Hasegawa, S., 
Mercaldo, V., Zhang, Y., Maeda, R., Ohta, M., Josselyn, S. A., Zhuo, M., and Kida, S. (2011). Upregulation of CREB-mediated transcription enhances both short- and long-term memory. The Journal of Neuroscience: The Official Journal of the Society for Neuroscience, 31(24), 8786-8802. https://doi.org/10.1523/JNEUROSCI.3257-10.2011

Swinton, E., de Freitas, E., Swinton, C., Shymansky, T., Hiles, E., Zhang, J., Rothwell, C., and Lukowiak, K. (2018). Green tea and cocoa enhance cognition in Lymnaea. Communicative and Integrative Biology, 11(1), e1434390. https://doi.org/10.1080/19420889.2018.1434390

Tronson, N. C., and Taylor, J. R. (2007). Molecular mechanisms of memory reconsolidation. Nature Reviews Neuroscience, 8(4), 262-275. https://doi.org/10.1038/nrn2090

Tully, T., Bourtchouladze, R., Scott, R., and Tallman, J. (2003). Targeting the CREB pathway for memory enhancers. Nature Reviews. Drug Discovery, 2(4), 267 277. https://doi.org/10.1038/nrd1061

Vauzour, D., Vafeiadou, K., Rice-Evans, C., Williams, R. J., and Spencer, J. P. E. (2007). Activation of pro-survival Akt and ERK1/2 signalling pathways underlie the anti-apoptotic effects of flavanones in cortical neurons. Journal of Neurochemistry, 103(4), 1355-1367. https://doi.org/10.1111/j.14714159.2007.04841.x

Widmer, Y. F., Bilican, A., Bruggmann, R., and Sprecher, S. G. (2018). Regulators of Long-Term Memory Revealed by Mushroom Body-Specific Gene Expression Profiling in Drosophila melanogaster. Genetics, 209(4), 1167-1181. https://doi.org/10.1534/genetics.118.301106

Williams, R. J., and Spencer, J. P. E. (2012). Flavonoids, cognition, and dementia: Actions, mechanisms, and potential therapeutic utility for Alzheimer disease. Free Radical Biology and Medicine, 52(1), 35-45. https://doi.org/10.1016/j.freeradbiomed.2011.09.010

Wilson, A. E., and Ross, M. (2003). The identity function of autobiographical memory: Time is on our side. Memory (Hove, England), 11(2), 137-149. https://doi.org/10.1080/741938210 
879 Yevchak, A. M., Loeb, S. J., and Fick, D. M. (2008). Promoting Cognitive Health and

880

881

882

883

884

885

886

887

888

889

890

891
Vitality: A Review of Clinical Implications. Geriatric Nursing, 29(5), 302310. https://doi.org/10.1016/j.gerinurse.2007.10.017

Yin, J. C., and Tully, T. (1996). CREB and the formation of long-term memory. Current Opinion in Neurobiology, 6(2), 264-268. https://doi.org/10.1016/S0959-4388(96)80082-1

Yoshida, M., Sakai, T., Hosokawa, N., Marui, N., Matsumoto, K., Fujioka, A., Nishino, H., and Aoike, A. (1990). The effect of quercetin on cell cycle progression and growth of human gastric cancer cells. FEBS Letters, 260(1), 10-13. https://doi.org/10.1016/0014-5793(90)80053-1

Zlotnik, G., and Vansintjan, A. (2019). Memory: An Extended Definition. Frontiers in Psychology, 10. https://doi.org/10.3389/fpsyg.2019.02523 
A<smiles>COCOCCOCCO</smiles>

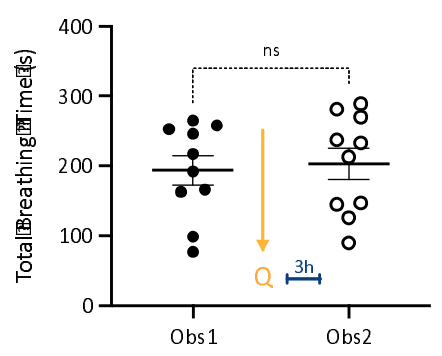

C

893

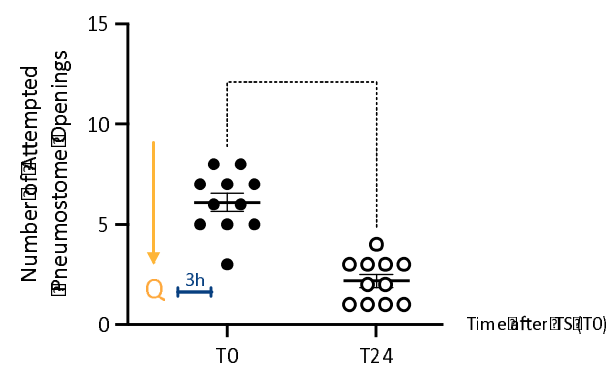

B
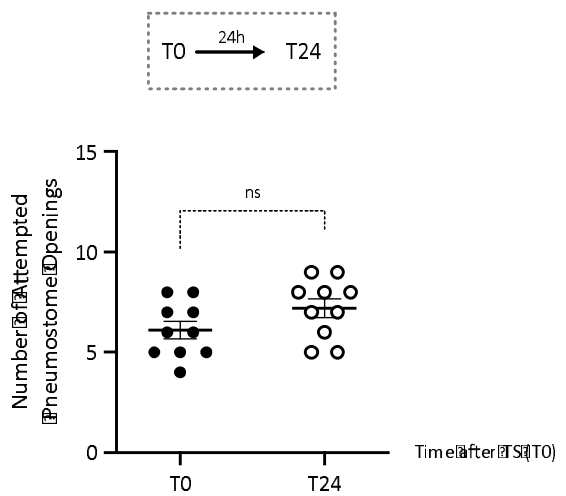

D

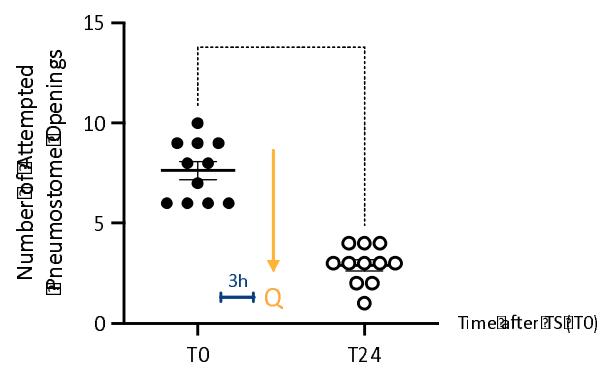

894 Fig. 1. Quercetin exposure and aerial respiration.

895 (A) Aerial respiratory behaviour in Lymnaea is not significantly altered by Q. We plotted and compared the total breathing time (TBT) between the first observation period (Obs1 - closed circles) and the second one performed 24h later, 3h after the exposure to Q (Obs2 - open circles).

899

(B) Snails given a $0.5 \mathrm{~h}$ TS in hypoxic PW do not form LTM. A naïve cohort of snails $(\mathrm{N}=10)$ received a $0.5 \mathrm{~h}$ training session $(\mathrm{T} 0$ - closed circles) and LTM was tested 24h later (T24 - open circles).

902

(C) The exposure to $\mathrm{Q} 3 \mathrm{~h}$ before a $0.5 \mathrm{~h}$ training session enhances LTM formation. A naïve cohort of snails $(\mathrm{N}=10)$ was exposed to $\mathrm{Q}$ for $1 \mathrm{~h}$ and $3 \mathrm{~h}$ later received a 
904

905

906

907

908

909

910

911

912

913
A

$$
\text { T0 } \stackrel{24 \mathrm{~h}}{\longrightarrow} \underset{\text { poke }}{\text { Single震 24h }} \longrightarrow \text { T48 }
$$

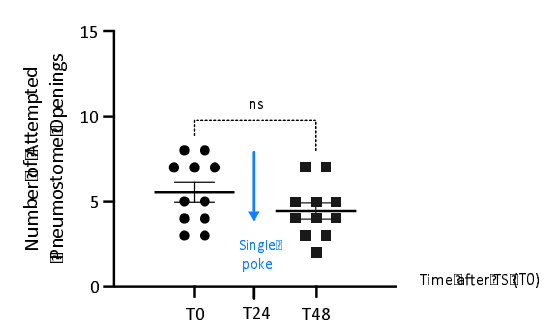

C

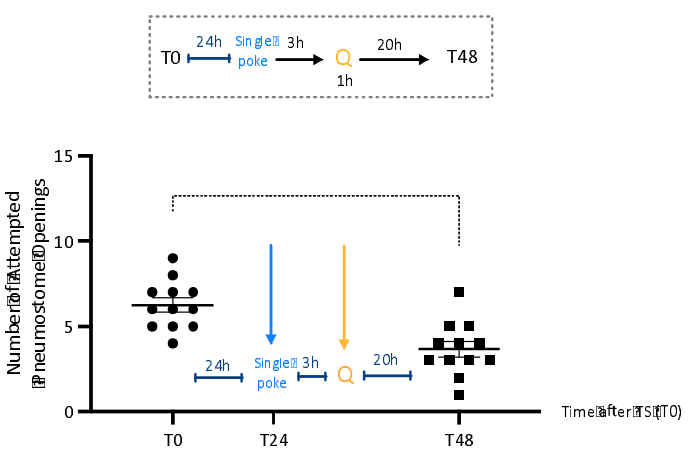

B

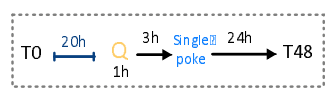

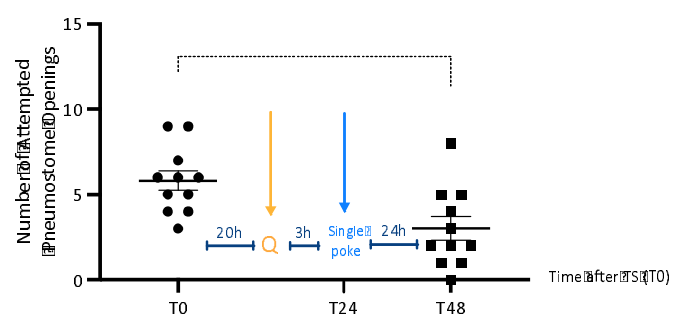

D
914

915

916

917

Fig. 2. The single poke procedure, quercetin exposure, and enhanced LTM formation.

(A) Snails receiving the single poke procedure $24 \mathrm{~h}$ before the $0.5 \mathrm{~h}$ training session do not form LTM. A naïve cohort of snails $(\mathrm{N}=11)$ received a $0.5 \mathrm{~h}$ training session 
918 (T0 - closed circles). 24h later animals received the 'singe poke' procedure and 919 24h later were tested for LTM (T48 - closed squares).

920 (B) The exposure to Q $3 \mathrm{~h}$ before the 'single poke' procedure occurring $24 \mathrm{~h}$ after the $921 \quad 0.5 \mathrm{~h}$ training session enhanced LTM formation. A naïve cohort of snails $(\mathrm{N}=11)$ 922 received a $0.5 \mathrm{~h}$ training ( $\mathrm{T} 0$ - closed circles) and $20 \mathrm{~h}$ later was exposed to $\mathrm{Q}$ for $923 \quad 1 \mathrm{~h}$. $3 \mathrm{~h}$ later snails received the single poke procedure and at T48 were tested for 924 LTM (closed squares).

925 (C) The exposure to Q $3 \mathrm{~h}$ after the 'single poke' procedure occurring $24 \mathrm{~h}$ after a $0.5 \mathrm{~h}$ 926 training session enhanced LTM formation. A naïve cohort of snails $(\mathrm{N}=11)$ 927 received a $0.5 \mathrm{~h}$ training ( $\mathrm{T} 0$ - closed circles) and $24 \mathrm{~h}$ later was subjected to the 928 single poke procedure. 3h later snails were exposed to $\mathrm{Q}$ for $1 \mathrm{~h}$ and $20 \mathrm{~h}$ later (at T48 - closed squares) were tested for LTM.

930 (D) The exposure to Q 20h after the single poke procedure does not result in enhanced 931 LTM formation. 24h after the 0.5h training session (T0 - closed circles), naïve 932 snails $(\mathrm{N}=10)$ were subjected to the single poke procedure. Q exposure occurred 933 20h later, 3h before LTM was tested at T48 (closed squares).

934 The timeline for each experiment is presented above the data. The solid line is the 935 mean, and the error bars are the s.e.m. Comparisons were made by paired t-test. ns = 936 not significant; $* \mathrm{p}<0.05 ; * * * * \mathrm{p}<0.0001$ 


\section{A}
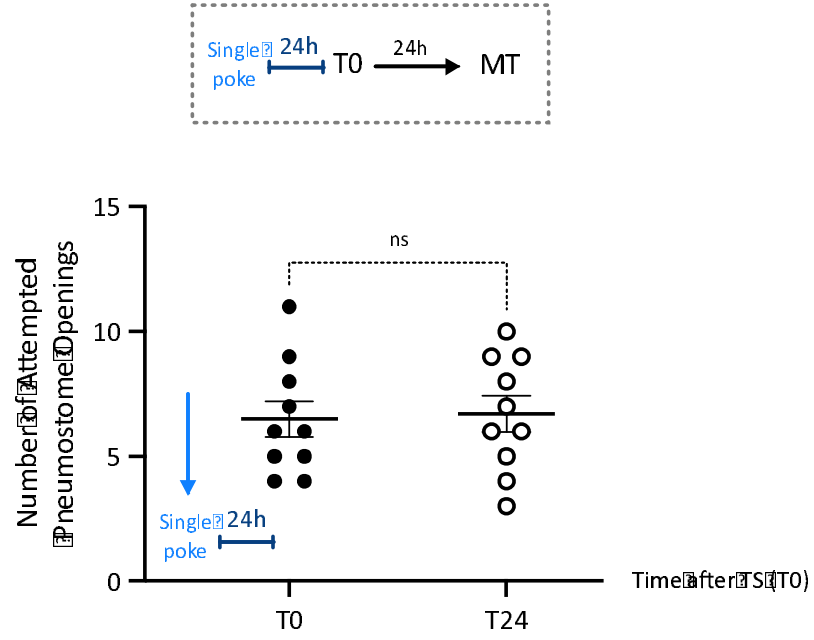

B

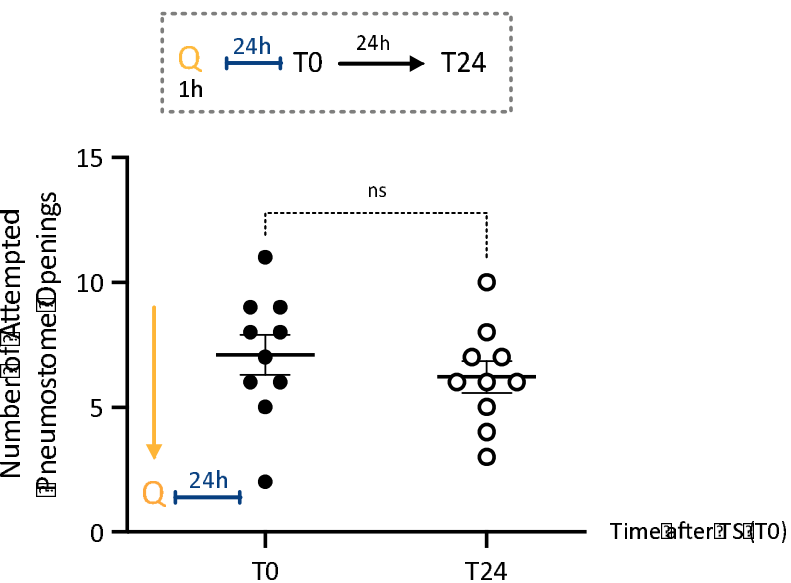

938 Fig. 3. The single poke procedure or Q-exposure $24 \mathrm{~h}$ before a $0.5 \mathrm{~h}$ training session 939 does not result in LTM formation.

940 (A) When applied $24 \mathrm{~h}$ before a $0.5 \mathrm{~h}$ training session, the single poke procedure does

941 not result in LTM formation. Snails were trained (T0 - closed circles) $24 \mathrm{~h}$ after

942 receiving the single-poke procedure and LTM was tested at T24 (open circles).

943 (B) When applied 24h before the 0.5h training session, Q-exposure does not result in

944 LTM formation. Snails were exposed to $\mathrm{Q}$ for $1 \mathrm{~h}$ and $24 \mathrm{~h}$ later received a $0.5 \mathrm{~h}$ 945 training session (T0 - closed circles). LTM was tested at T24 (open circles). 
946 The timeline of each experiment is presented above the data. Comparisons were

947 made by paired t-test. The solid line is the mean, and the error bars are the s.e.m. ns = 948 not significant.

949

A

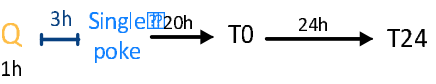

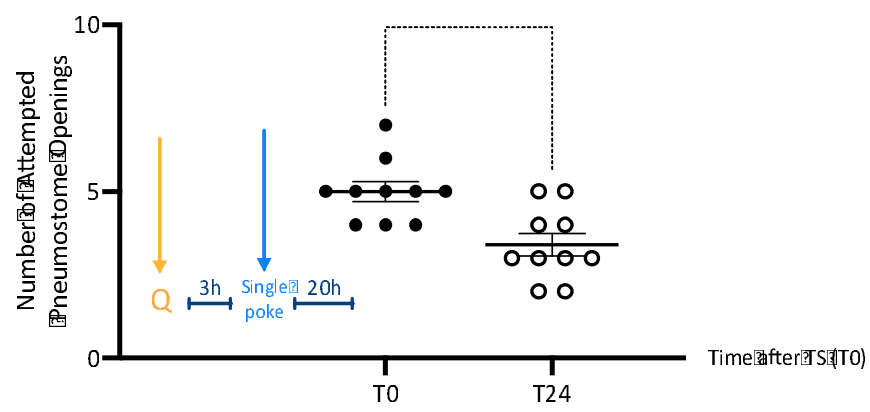

B

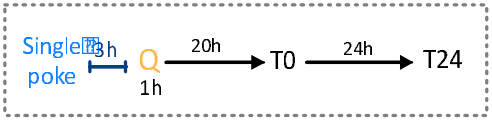

950

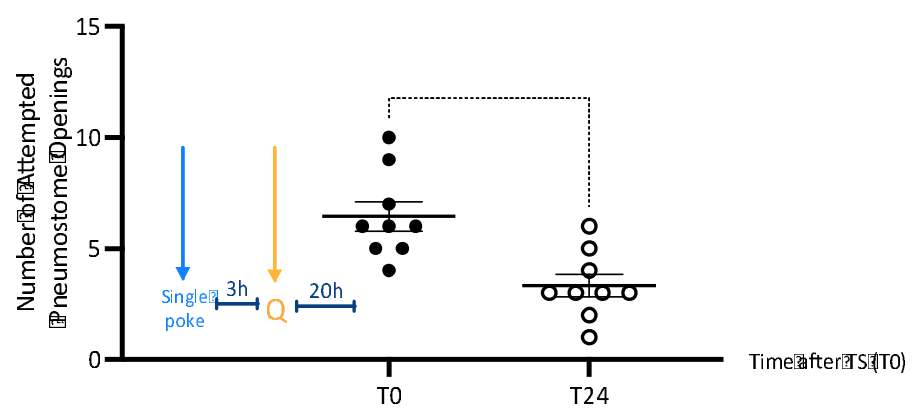

951 Fig. 4. The single poke procedure combined with Q-exposure $3 \mathrm{~h}$ before a $0.5 \mathrm{~h}$ 952 training session results in enhanced LTM formation.

953 (A) The exposure to $\mathrm{Q} 3 \mathrm{~h}$ before the single poke procedure performed before the 954 single training results in LTM. A naïve cohort of snails $(\mathrm{N}=10)$ was exposed to $\mathrm{Q}$ for $9551 \mathrm{~h}$ and $3 \mathrm{~h}$ later received the single poke procedure. 20h later, animals were trained 956 (T0 - closed circles) and LTM was tested at 24h (T24 - open circles). 
957 (B) The exposure to Q $3 \mathrm{~h}$ after the single poke procedure performed before the single 958 training results in LTM. A naïve cohort of snails $(\mathrm{N}=9)$ received the single poke 959 procedure and $3 \mathrm{~h}$ later was exposed to Q for $1 \mathrm{~h}$. 20h later, animals were trained (T0 960 closed circles) and LTM was tested at T24 (open circles).

961 The timeline of each experiment is presented above the data. Comparisons were 962 made by paired t-test. $* * * * p<0.0001 ; * \mathrm{p}<0.05$ 


$$
\text { Obs } 1 \stackrel{20 \mathrm{~h}}{\longrightarrow} \underset{1 \mathrm{~h}}{\mathrm{Q}} \stackrel{3 \mathrm{~h}}{\longmapsto} \text { Obs } 2
$$

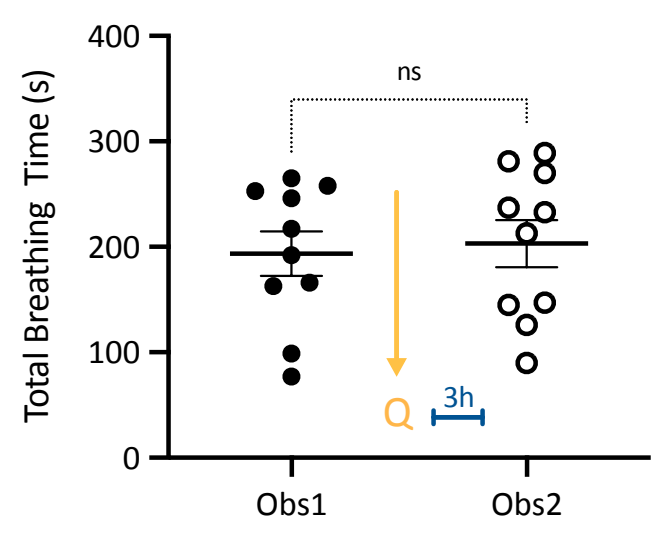

C

$$
\underset{1 \mathrm{~h}}{\mathrm{Q}} \stackrel{3 \mathrm{~h}}{\longmapsto} \mathrm{T0} \stackrel{24 \mathrm{~h}}{\longrightarrow} \mathrm{T} 24
$$

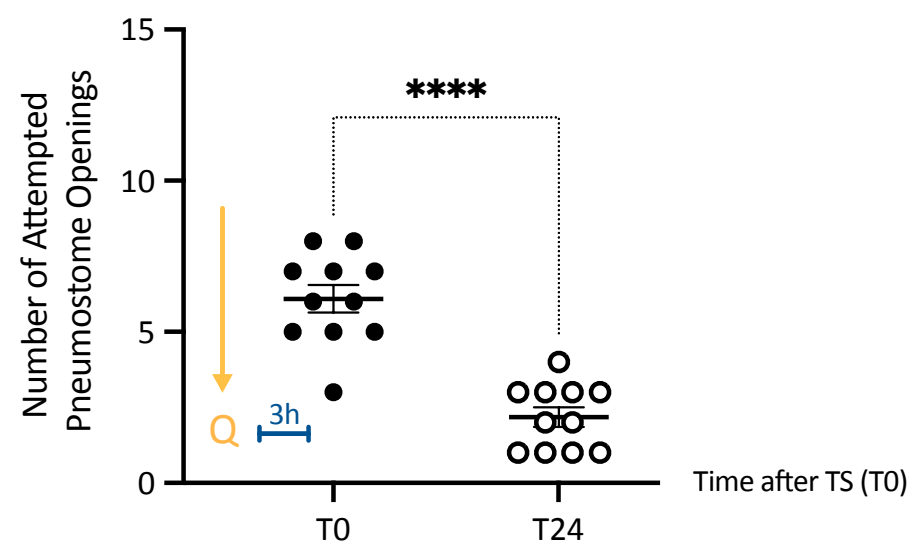

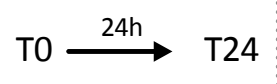

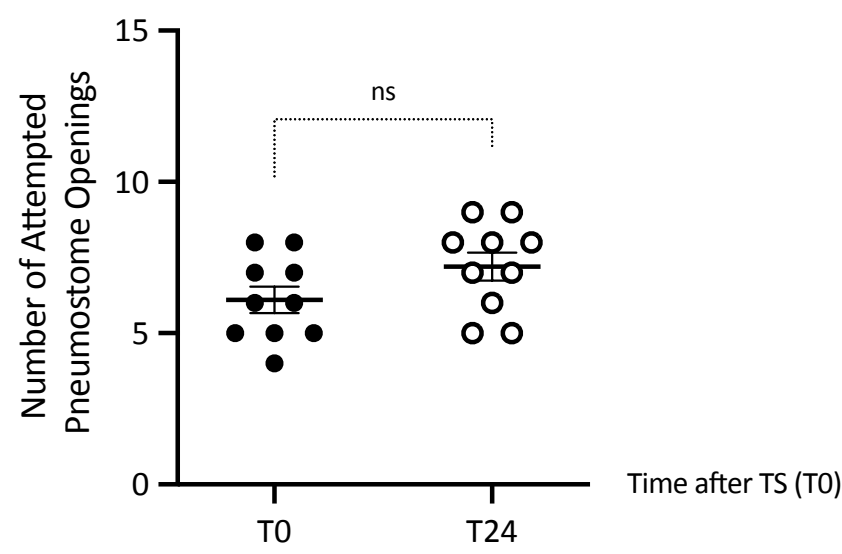

D
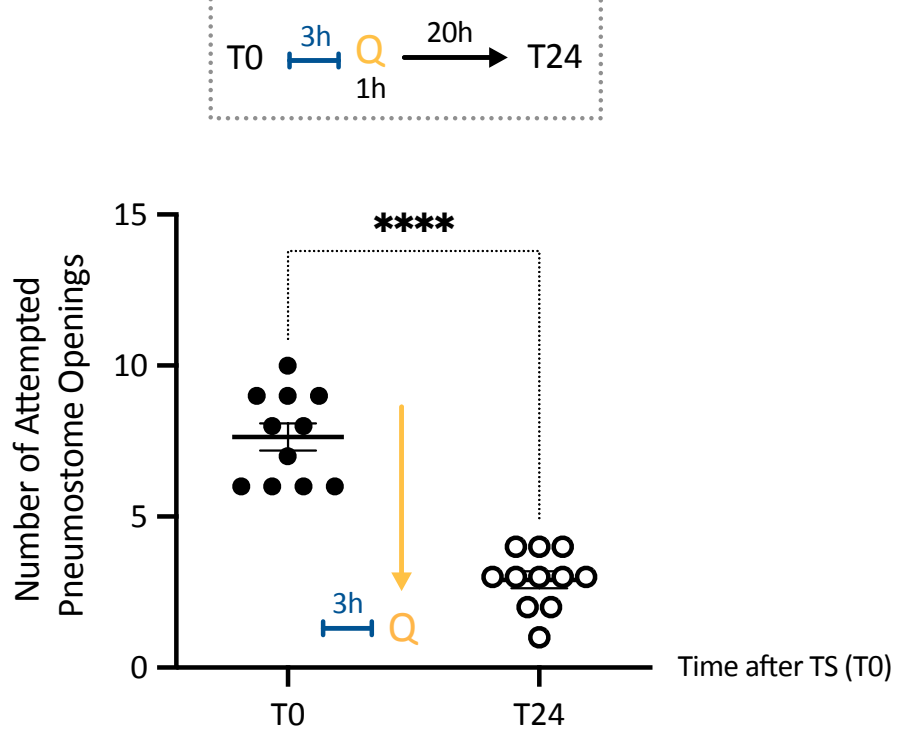


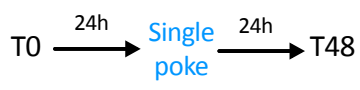

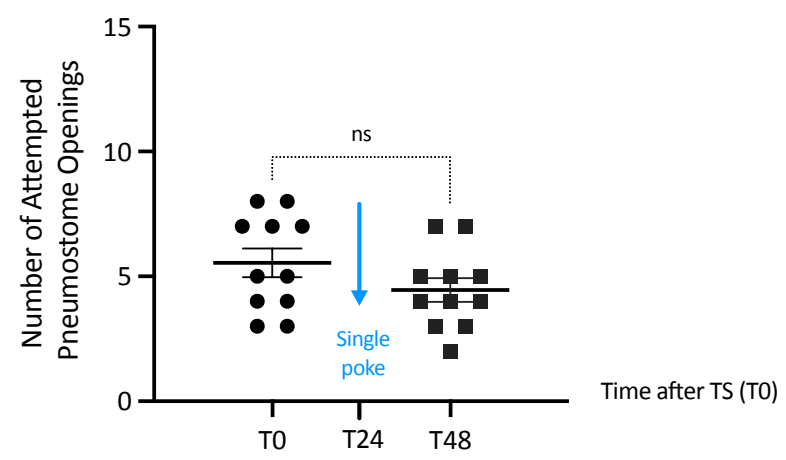

C
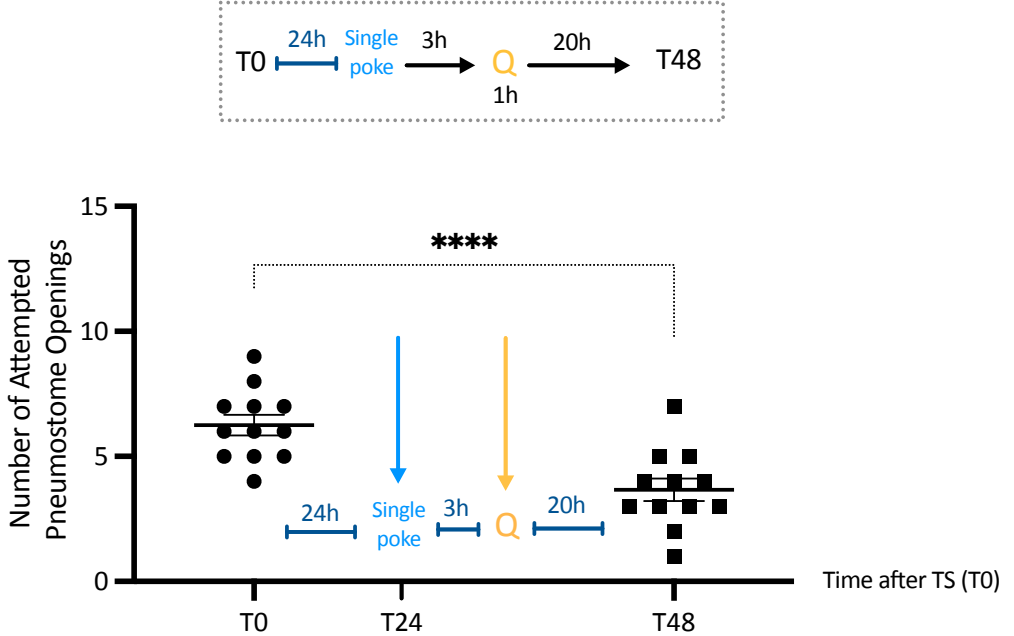

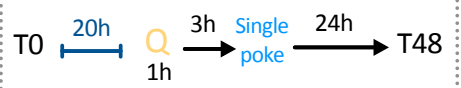

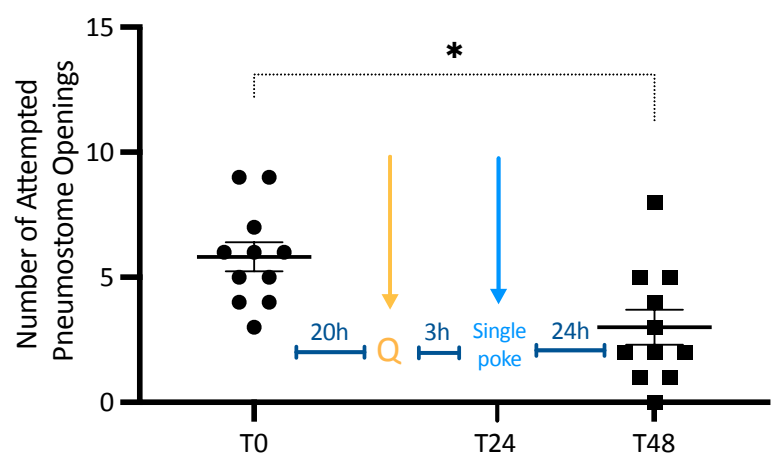

Time after TS (TO)

D
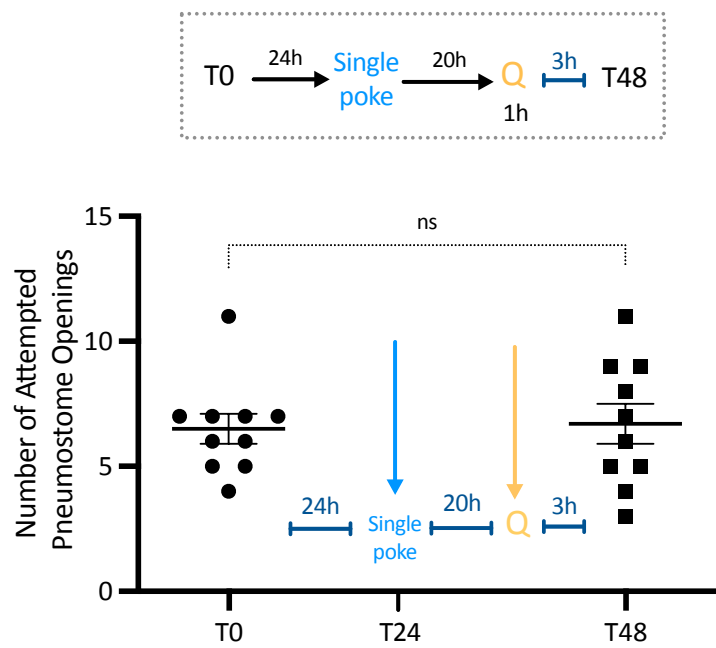


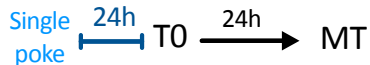

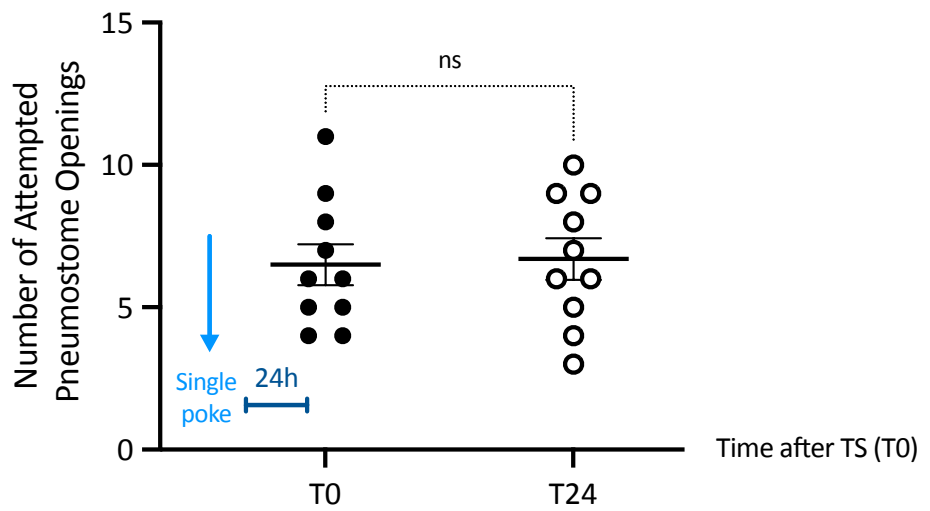

B
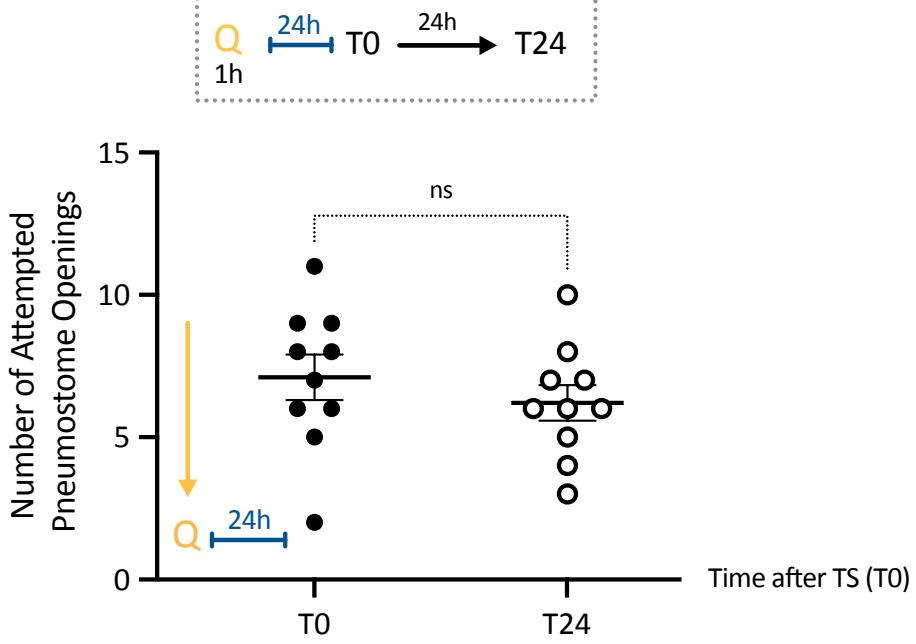


$$
\stackrel{3 \mathrm{~h}}{\longmapsto} \text { poke } \stackrel{\text { Single }}{20 \mathrm{~h}} \longrightarrow \text { T0 } \stackrel{24 \mathrm{~h}}{\longrightarrow} \text { T24 }
$$

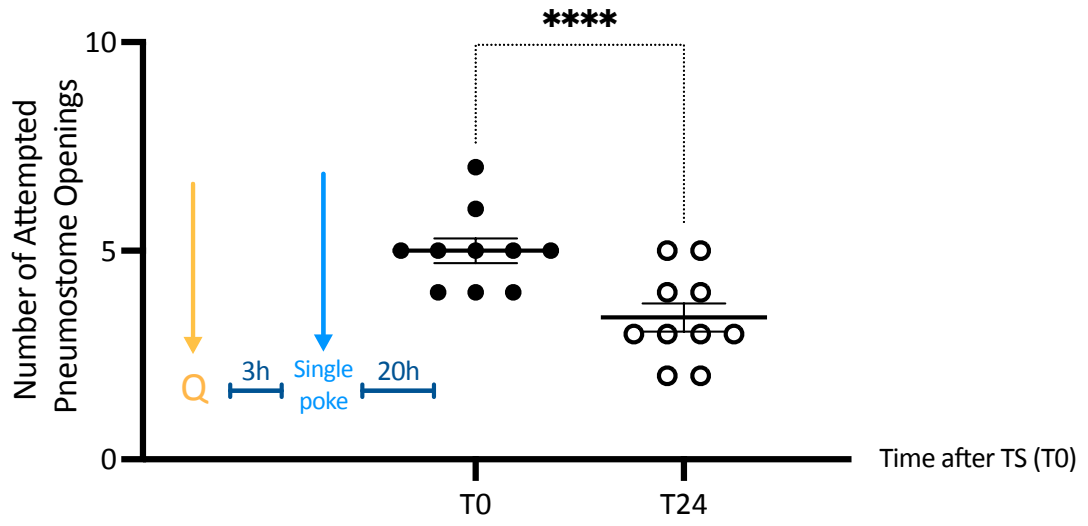

$$
\underset{\text { poke }}{\stackrel{\text { Single }}{\longmapsto}} \underset{1 \mathrm{~h}}{\mathrm{Q}} \stackrel{2 \mathrm{~h}}{\longrightarrow} \mathrm{T} 0 \stackrel{24 \mathrm{~h}}{\longrightarrow} \mathrm{T} 24
$$

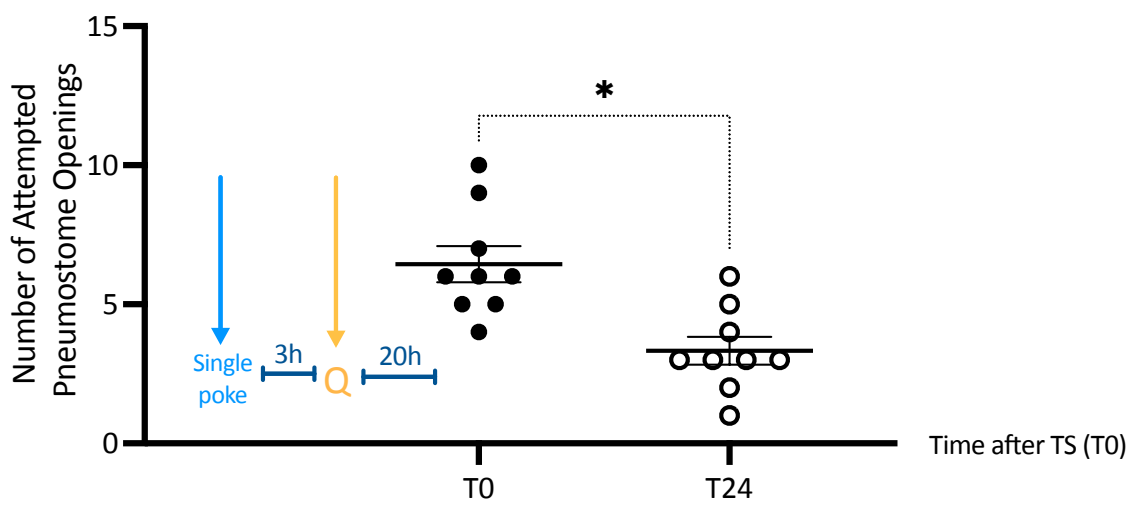

